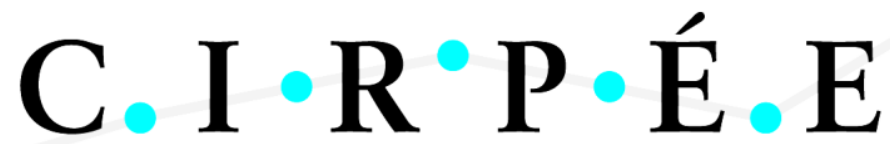

Centre Interuniversitaire sur le Risque, les Politiques Économiques et l'Emploi

Cahier de recherche/Working Paper 10-29

\section{The Impact of Inflation Targeting : Testing the Good Luck Hypothesis}

\author{
Federico Ravenna
}

Septembre/September 2010

Ravenna: Department of Economics, University of California - Santa Cruz, Institute of Applied Economics, HEC Montréal and CIRPÉE

fravenna@ucsc.edu

I would like to thank Luca Benati, Thomas Cooley, Mark Gertler, Bart Hobijn, Oscar Jorda, Peter Ireland, Giorgio Primiceri, Francisco Ruge-Murcia, Paolo Surico and Carl Walsh for helpful discussion on earlier drafts of this project. Lorena Saiz Matute provided excellent research assistance. 


\begin{abstract}
:
Over the last twenty years the level and volatility of inflation decreased across industrial countries. The inflation stabilization can be explained by a shift in monetary policy or by a lucky period of low volatility in business cycle shocks. To test the "luck hypothesis" we examine the inflation experience of Canada, one of the earliest and most successful adopters of an inflation targeting monetary policy. We Kalman-filter the historical structural shocks consistent with an estimated DSGE model. The estimated shocks are used to build counterfactual histories. Ex-ante the model predicts inflation volatility to more than halve under inflation targeting. But conditional on the shocks, we show that the luck hypothesis can explain with a high probability Canada's low inflation volatility since the early 1990s. Any inflation stabilization induced by the shift in policy is accounted for the most part by the impact on expectations. Counterfactuals built neglecting expectations would prove the inflation targeting policy irrelevant.
\end{abstract}

Keywords: Business cycle shocks, Kalman filter, Credibility, Inflation targeting

JEL Classification: E42, E52, E58 


\section{Introduction}

Over the last twenty years industrial countries have experienced a marked decline in the level and volatility of inflation, interest rates, and long term inflation expectations. The recent period of low and stable inflation can be attributed either to a change in the propagation mechanism of the economy the most prominent explanation being a shift in the management of monetary policy - or to a reduction in the volatility of exogenous shocks.

What are the reasons behind the observed change in inflation behaviour across industrial countries? This paper examines the inflation performance of Canada, an early and successful adopter of an inflation targeting monetary policy since February 1991, and asks whether it can be explained by the 'luck hypothesis'. Accepting the luck hypothesis means that conditional on the exogenous shocks that hit the Canadian economy since 1991 the inflation time series would not have been significantly different under an alternative monetary policy. We focus on the impact of inflation targeting in reducing inflation volatility, which dropped in Canada from 2.28 over the 1981-1990 decade to 0.51 over the following 1991-2000 decade, and to 0.48 over the 1991-2005 period (year-over-year core CPI inflation measured at monthly frequency, reported in Longworth, 2002, Murray, 2006). Our estimates show that the luck hypothesis cannot be rejected. At the same time, nearly all of the impact of inflation targeting on the behaviour of inflation was caused by the change in the private sector's beliefs for monetary policy. The results are based on a methodology that builds upon, and expands on, a vast literature on constructing historical counterfactuals using restrictions from DGSE models.

The experience of inflation targeting countries is especially suitable to assess whether good luck or good policy can account for the observed change in inflation behaviour across industrial countries, since the monetary authority explicitly announced - and committed to - the inflation targeting policy. Countries adopting inflation targeting have experienced lower and more stable inflation, and a decline in the volatility of a wide range of other macroeconomic indicators. On the contrary, in the US case the existence of a shift in monetary policy regime over the last 25 years is still widely debated. ${ }^{1}$

Canada adopted inflation targets in 1991, aimed at stabilizing inflation around a long-term level of $2 \%$. The change in policy happened at a time when inflation was feared to escalate again after the

\footnotetext{
${ }^{1}$ While Boivin and Giannoni (2006), Cogley and Sargent (2005) and Clarida et al. (2000) provide evidence that US monetary policy did change in the $1980 \mathrm{~s}$, and affected the observed behaviour of inflation, the results in a number of papers do not support the claim of a shift in the systematic behaviour of US monetary policy, or the claim that it was responsible for the observed decline in real activity volatility (Ahmed, Levin and Wilson, 2004, Bernanke and Mihov, 1998, Canova and Gambetti, 2006, Justiniano and Primiceri, 2006, Primiceri, 2005, Sims and Zha, 2006, Stock and Watson, 2003).
} 
significant reduction achieved in the 1982-84 period, following the economic boom at the end of the 1980s, an oil-price shock, and the introduction of a value added tax. A number of studies (Longworth, 2002, Ravenna, 2009) have documented that since 1991 there have been profound changes in the behaviour of inflation - beside its lower average level - including changes in its volatility, persistence, predictability, and in the slope of the Phillips curve. The average value of one measure of inflation uncertainty fell from 2.43 in 1981-1990 to 1.15 in 1991-2000, and the range of the forecast for long term inflation, a measure of dispersion in inflation expectations, fell from 6.55 to 2.91 across the two subsamples (Longoworth, 2002). An important objective of the inflation targeting policy is to reinforce the stability of the inflation process. The Bank of Canada itself documents that "the short run response of inflation to measures of excess demand and supply appears to have fallen" (Dodge, 2002). ${ }^{2}$ Finding cross country evidence that inflation targeting improves macroeconomic performance has been challenging (Ball and Sheridan, 2005, Cecchetti and Debelle, 2006, Goncalves and Carvalho, 2009, Levin, Natalucci and Piger, 2004), raising the possibility that the observed inflation stability was the result of good luck shared across industrial countries. Yet cross country evidence on the impact of inflation targeting may be hard to come by because aversion to inflation variability increased across most industrial countries since the 1980s (for cross country comparisons, see Bernanke, Laubach, Mishkin and Posen, 1999, Cecchetti and Ehrmann, 2002, Mishkin, 1999, Mishkin and Schmidt-Hebbel, 2002, Neumann and von Hagen, 2002, and Truman, 2003).

We investigate the impact of the shift in monetary policy by building counterfactual histories of the Canadian economy since the adoption of inflation targeting conditional on the earlier monetary policy and on a vector of shocks Kalman-filtered from data on ten aggregate variables. The shocks vector and the counterfactual history are constrained to be consistent with a maximum likelihoodestimated staggered wage and price adjustment DSGE model of the economy.

Contrary to counterfactuals built from VAR reduced-form models, as in Ahmed, Levin and Wilson (2004), Canova and Gambetti (2009), Primiceri (2005), Sims and Zha (2006), our approach allows for the policy change to affect the private sector's expectations. Since a stated goal of inflation targeting central banks has been to change inflation expectations, the VAR reduced-form approach is likely to provide a distorted picture (see Benati and Surico, 2009). Our methodology is closer to the approach used by King and Rebelo (1998), Justiniano and Primiceri (2006), Rotemberg and Woodford (1998), and similar to the 'business cycle accounting' in Chari, Kehoe and McGrattan (2007).

\footnotetext{
${ }^{2}$ Admittedly, core inflation standard deviation had been quite low in the second half of the 1980s, but it was even lower in the second half of the 1990s, with the point estimates for the two subperiods equal to 0.58 and 0.33 .
} 
As in the accounting approach, we take as a starting point a DSGE model, but we also allow for the possibility that the model may be too stylized to describe the data dynamics. Thus we introduce an additional vector of disturbances that identifies sources of fluctuations beyond the ones summarized in the DSGE model, and estimate the DSGE structural shocks with a Kalman filter. This same methodology is used by Christiano, Motto and Rostagno (2008), and is related to Ireland (2004) and Boivin and Giannoni (2006), and to the technique to estimate DSGE models in Sargent (1989). We provide a comparison of the results under three alternative methodologies. Our estimation shows that forcing the DSGE model to explain all the volatility in the data would overturn the result from the counterfactual exercise. Neglecting the policy impact on expectations would also bias the result from the counterfactual exercise.

We innovate relative to the Kalman filtering literature by showing two alternative ways to build counterfactuals so as to evaluate how much of the economy dynamics in the inflation targeting period is accounted for by the change in the path of the policy instrument (a shift in the actual policy) and by the announcement of an inflation target that is credible and affects expectations (a shift in the perceived policy)

Finally, we provide an explicit metric to evaluate the likelihood of the luck hypothesis. To test the luck hypothesis we ask what was the probability of observing the counterfactual inflation history conditional on the inflation targeting policy. In this way we can evaluate whether the counterfactual path would have been a more or less likely draw given the estimated variance of the shocks.

The main conclusions we reach are as follows.

With a high probability good luck can explain the low inflation volatility throughout the inflation targeting period in Canada. This result obtains despite model estimates implying the unconditional expected volatility of inflation to more than halve in the inflation targeting regime. We do not interpret the evidence for the luck hypothesis as implying that monetary policymaking is irrelevant. Inflation targeting simply may have not been put to test by inflationary shocks. But our result does support the good luck over good policy explanation, and - contrary to a vast literature on the impact of inflation targeting - implies that the shift in monetary policy cannot account for the historical improvement in inflation performance. While policies may be judged more or less desirable based on their unconditional properties, the historical evaluation of their performance is only meaningful if conditioned on the business cycle shocks.

The counterfactuals show that inflation targeting affected the behaviour of inflation for the largest part through the impact on expectations. Monetary policy shocks are estimated to have non- 
negligible variance, yet they contributed very little to inflation stabilization. Moreover, a monetary policy that did not affect private sector expectations but nevertheless stabilized inflation at its historical level would have lead to a severe and prolonged recession. This result supports the claim that changes in policy regime can dramatically affect the economy dynamics by altering private agents' decisionmaking (Sargent, 1999), and the empirical observation that inflation targeting in Canada managed to de-couple inflation expectations from recently observed inflation rates (Dodge, 2002).

As for the methodological contribution, our result that alternative approaches to build counterfactuals can overturn the evaluation of the luck hypothesis illustrates the importance of allowing for a vector of non-structural disturbances when filtering the historical business cycle shocks. The Kalman filtering approach we adopt allows the data to choose what is the portion of business cycle volatility that the DSGE model can explain. Our methodology to assess the impact of a change in the path of the policy instrument separately from the impact of a change in the private sector expectation of policy can be applied to measure the announcement effect of any change in policymakers' behaviour.

The paper is organized as follows. Section 2 compares alternative methods to build counterfactual histories and presents our empirical strategy. Section 3 presents the model. Section 4 explains the building of the Kalman-filtered counterfactual. Section 5 discusses the maximum likelihood estimation of the model and builds counterfactuals histories to evaluate the role of the policy rule, the role of policy shocks, and the role of credibility on Canadian inflation performance, and to assess the luck hypothesis. The implications of alternative methodologies are discussed. Section 6 concludes.

\section{Counterfactual Histories to Evaluate the Impact of Policy Changes}

A counterfactual history is defined by two components: a series of historical shocks $\varepsilon_{t}$ and a counterfactual law of motion. This section considers a baseline case to illustrate our empirical approach. Section 4 discusses the general case, and Appendix 7.3 provides the derivation of the equations in the following.

Let the rational expectation equilibrium law of motion for a linearized DSGE model be given by the first order non-singular VAR process:

$$
Y_{t}=\Gamma_{1} Y_{t-1}+\Gamma_{2} \varepsilon_{t}
$$

where $Y_{t}=\left[y_{t}, x_{t}\right]^{\prime}, y_{t}$ is a vector of endogenous control variables, $x_{t}$ is a vector of endogenous state variables, $\varepsilon_{t}$ is vector of exogenous shocks randomly distributed. The VAR approach to generate a counterfactual history starts with estimation of the matrices $\Gamma_{1}, \Gamma_{2}$, and uses the reduced-form model 
(1) to build the historical shocks $\left[\varepsilon_{t}\right]_{t=1}^{T}$. Couterfactuals are built by changing the coefficients in the row of $\Gamma_{1}, \Gamma_{2}$ corresponding to the policy rule adopted, while expectations are assumed invariant to policy. 3 Benati and Surico (2009) have shown that the VAR approach can have low power in discriminating between structural changes in the economy and changes in the exogenous shocks variance.

Our strategy is to derive the equilibrium law of motion (1) from estimation of a DSGE model, and then use the DSGE reduced-form model to construct the historical shocks $\left[\varepsilon_{t}\right]_{t=1}^{T}$. This approach has been adopted by various authors, among which Arias, Hansen and Ohanian (2007), Benati and Mumtaz (2008), Justiniano and Primiceri (2006), King and Rebelo (1998), Rotemberg and Woodford (1998), Stock and Watson (2003) ${ }^{4}$. Chari, Kehoe and McGrattan (2007) use a similar methodology, although the 'business cycle accounting' they propose identifies time-varying wedges in equilibrium decision-rules consistent with a whole family of models, rather than structural shocks from a uniquely identified model. Because this approach estimates the structural coefficients of the DSGE model, it is possible to build the counterfactual law of motion by solving the DSGE model conditional on the alternative policy. Therefore, all the elements of $\Gamma_{1}, \Gamma_{2}$ are allowed to change, and expectations are model-consistent.

An important drawback of this methodology is that by construction it requires a small set of structural shocks and the model internal propagation mechanism to explain all the volatility in the data. It is an accounting approach that does not allow for deviations from the DSGE model law of motion when building the model-consistent shocks vector. This requirement can be very taxing for the stylized models used in the DSGE literature. The Kalman filtering approach (Christiano, Motto and Rostagno, 2008, Ireland, 2004) allows for the existence of an additional vector of disturbances $w_{t}$ uncorrelated with $\varepsilon_{t}$. The vector $w_{t}$ identifies sources of fluctuations beyond the shocks included in the DSGE model, which are given a structural interpretation. The law of motion for the observable variables is then:

$$
Y_{t}=\Gamma_{1} Y_{t-1}+\Gamma_{2} \varepsilon_{t}+w_{t}
$$

In essence eq. (2) augments the DSGE model so that there exists a residual variance in the data that the model is not called to explain in terms of movements of the structural shocks. This approach thus

\footnotetext{
${ }^{3}$ For applications of this approach, see Bernanke et al. (1999), Mishkin and Posen (1997), Canova and Gambetti (2009), Sims and Zha (2006). It is possible to build VAR counterfactuals where expectations are policy-consistent, as in Ahmed, Levin and Wilson (2004) and Primiceri (2005). But in this case there is no assurance that the VAR counterfactual accounts exclusively for a change in the policy rule.

${ }^{4}$ These authors use the state-space representation of the equilibrium law of motion rather than the VAR representation. The state-space representation does not require that the vector $x_{t}$ be observable to obtain the historical series $\varepsilon_{t}$. Ravenna (2007) discusses conditions for a finite order VAR representation of a DSGE model equilibrium law of motion to exist.
} 
allows for part of the observable variables' variance to be explained by the vector $w_{t}$ when estimating the model-consistent shocks vector, while it uses exclusively the DSGE model to build a counterfactual path with model-consistent expectations.

Empirical research using counterfactual histories to ascertain whether the change in the observed time-series of a macroeconomic aggregate must be ascribed to a change in exogenous shocks or behavioral parameters typically uses data before and after the observed change. We adopt a more parsimonious approach, and only use data after the adoption of inflation targeting in Canada. Thus we cannot discuss what was the cause of the observed change in inflation volatility before and after the inflation targeting policy adoption - whether, for example, the volatility of exogenous shocks did change across subsamples - but we can test whether the change in monetary policy was relevant or not for the behaviour of inflation volatility in the inflation targeting period. It may very well be that inflation targeting would have lowered inflation volatility in the earlier sample, or that the shocks from the earlier sample would have lead to high inflation volatility despite the switch to inflation targeting. These claims are distinct from the hypothesis we test, and are conditional on an estimated shocks' vector that was never faced by the monetary authority in the inflation targeting period.

Our approach does not require estimation of the DSGE model over two subsamples - for the preinflation targeting period, only an estimate of the policy rule is needed . To impose as few constraints as possible on the data, we estimate the policy rule using a GMM estimator. The GMM estimator allows the use of a larger data set, which is useful since a number of time series used in the DSGE model estimation post-1991 are only available starting in $1984 .^{5}$

\section{The General Equilibrium Model}

The Canadian economy is modeled as a small open economy with nominal price rigidities, along the lines of the recent literature on monetary models of the international business cycle (see Bergin, 2003, Gali and Monacelli, 2005, Kollmann, 2001). The domestic $(H)$ sector utilizes labor to produce a consumption-good basket that is both consumed by domestic households and exported to the foreign $(F)$ sector, in exchange for a foreign-produced consumption good.

A fraction of households and domestic firms set respectively nominal wages according to the Erceg, Henderson and Levin (1999) staggered contracts mechanism, and prices as in Calvo (1983). The

\footnotetext{
${ }^{5}$ To obtain comparable estimates of the policy rule coefficients before and after the adoption of inflation tagerting, we estimate the policy rule with GMM over the two subsample, and estimate the DSGE model parameters given the inflation targeting policy rule estimates.
} 
remaining fraction is assumed to follow a rule of thumb, so that price and wage setting is partially backward-looking. Households' preferences have a habit-persistence specification. These three features improve the performance of sticky-price models, whose failure to generate plausible degrees of output and inflation persistence and to match the empirical correlation between real wages and output is well known (Fuhrer, 2000). Christiano, Eichenbaum and Evans (2005) and Rabanal and Rubio Ramirez (2005) provide evidence that nominal wage rigidity is at least as important as nominal price rigidity in accounting for US and Euro area business cycle fluctuations. Finally, the model allows for short-term incomplete pass-through from the foreign to the domestic price of imported goods.

\subsection{Consumption Good Aggregates}

Assume a continuum of infinitely lived households, indexed by $j \in[0,1]$. Domestic households can purchase a basket of differentiated home- and foreign-produced goods. The consumption aggregate $C_{t}$ combines the domestic $\left(C_{H}\right)$ and foreign $\left(C_{F}\right)$ goods basket in the same proportions as household $j$ would choose:

$$
C_{t}^{j}=\left[(1-\gamma)^{\frac{1}{\rho}}\left(C_{H, t}^{j}\right)^{\frac{\rho-1}{\rho}}+\gamma^{\frac{1}{\rho}}\left(C_{F, t}^{j}\right)^{\frac{\rho-1}{\rho}}\right]^{\frac{\rho}{\rho-1}}
$$

where $0 \leq \gamma \leq 1$ is the share of the foreign good and $\rho>0$ is the elasticity of substitution between domestic and foreign goods. The domestic good $H$ and the foreign good $F$ are Dixit-Stiglitz aggregates defined over a continuum of differentiated goods indexed by $i \in[0,1]$ with elasticity of substitution $\vartheta$. Households allocate their expenditure optimally across goods. $P_{t}, P_{H, t}$ and $P_{F, t}$ indicate the price indices for the aggregate, domestic and foreign good consumption basket.

\section{$3.2 \quad$ Firms}

The home production sector is made up of a continuum of firms indexed by $i \in[0,1]$. Domestic firms produce goods by combining labor services supplied by households. Firms regard each household $j$ 's labor supply $N_{t}^{j}$ as an imperfect substitute for the labor offered by other households. A CES labor

aggregator $N_{t}=\left(\int_{0}^{1} N_{t}^{j \frac{\phi}{\phi-1}} d j\right)^{\frac{\phi-1}{\phi}}$ combines households' labor services in the same proportions as firms would optimally choose. The wage index $W_{t}=\left(\int_{0}^{1} W_{t}^{j^{1-\phi}} d j\right)^{\frac{1}{1-\phi}}$ gives the least expenditure that buys a unit of the labor index. Firm $i$ optimal demand for each type of labor $j$, conditional on the total demand for labor services $N_{t}(i)$, is equal to:

$$
N_{t}^{j}(i)=\left(\frac{W_{t}^{j}}{W_{t}}\right)^{-\phi} N_{t}(i)
$$


The total cost of the differentiated labor services hired by firm $i$ is $\int_{0}^{1} N_{t}^{j}(i) W_{t}^{j} d j=N_{t}(i) W_{t}$. The firm producing good $i$ employs a CRS technology: $Y_{t}(i)=A_{t} N_{t}(i)$, where $A_{t}$ is an aggregate productivity shock. The firms' cost minimization problem implies that when inputs quantities are chosen optimally the real marginal cost $M C_{t}$ is independent of the scale of production. We adopt the hybrid pricing model in Gali and Gertler (1999). As in the time-dependent Calvo (1983) pricing model, in every period $t$ firms adjust their prices with probability $\left(1-\theta_{p}\right)$. A fraction $\left(1-\omega_{p}\right)$ of the price resetting firms update the price optimally, while a fraction $\omega_{p}$ follows a backward-looking rule of thumb. The problem of the firm optimally setting the price at time $t$ consists of choosing $P_{H, t}(i)$ to maximize

$$
E_{t} \sum_{s=0}^{\infty}\left(\theta_{p} \beta\right)^{s} \Lambda_{t, t+s}\left[\frac{P_{H, t}(i)}{P_{H, t+s}} Y_{H, t+s}(i)-\frac{M C_{t+s}^{N}}{P_{H, t+s}} Y_{H, t+s}(i)\right]
$$

subject to

$$
\begin{aligned}
Y_{H, t+s}(i) & =\left[\frac{P_{H, t}(i)}{P_{H, t+s}}\right]^{-\vartheta} C_{t+s}^{W} \\
M C_{t+s}^{N} & =P_{H, t+s} M C_{t+s}=\frac{W_{t+s}}{M P L_{t+s}}
\end{aligned}
$$

where $M C^{N}$ is the nominal marginal cost, $M P L$ is the marginal product of labor. In $(6), Y_{H, t+s}(i)$ is the demand function for firm $i$ output at time $t+s$, conditional on the price set $s$ periods in advance at time $t, P_{H, t}(i)$. Market clearing ensures that $Y_{H, t}(i)=C_{t}^{W}(i) \equiv C_{H, t}(i)+C_{H, t}^{*}(i)$ where $C_{H, t}^{*}(i)=\left(\frac{P_{H, t}(i)}{P_{H, t}}\right)^{-\vartheta} C_{H, t}^{*}$ is foreign demand for $\operatorname{good} i, C_{H, t}^{*}=\gamma^{*} C_{t}^{*}$ is foreign demand for domestic exports and $C_{t}^{*}$ is the exogenously given foreign aggregate demand for imports. Aggregate world demand is defined as $C_{t}^{W} \equiv C_{H, t}+C_{H, t}^{*}$. The stochastic discount factor between $t$ and $t+s$ is $\beta^{s} \Lambda_{t, t+s}$. Backward looking firms update their price to the average level set in the most recent round of price adjustment, $\bar{P}_{t-1}$, adjusted for the lagged domestically-produced goods inflation rate $\pi_{H, t-1}$ :

$$
P_{H, t}^{R T}(i)=\bar{P}_{H, t-1}\left(1+\pi_{H, t-1}\right)
$$

Conditional on the shocks vector at time $t$, the rule of thumb price $P_{H, t+k}^{R T}(i)$ converges to the optimal price as $k \rightarrow \infty$. This hybrid model ensures that current inflation is determined partly by lagged and partly by expected inflation. At the same time, contrary to the indexation model assumed, for example, in Christiano et al. (2005), it does not constrain all firms to change prices every period. 


\subsection{Households}

Households' preferences are described by the instantaneous utility function:

$$
U_{t}^{j}=\left\{\left[\ln \left(C_{t}^{j}-b C_{t-1}^{j}\right)\right] D_{t}-\frac{\ell N_{t}^{j^{1+\eta}}}{1+\eta}+\nu\left(\frac{M_{t}^{j}}{P_{t}}\right)\right\}
$$

where $M_{t} / P_{t}$ is real money balances, $N_{t}$ is the amount of labor service supplied, $D_{t}$ is an exogenous preference shock that distorts the labor-leisure decision. Hall (1997) defines this shock as a shift in "households' choice between work in the market and time spent in non-market activities". When $b>0$ preferences are characterized by habit persistence. State-contingent claims ensure consumption levels are identical across households who supply different amounts of labor services. The aggregate consumption risk cannot be fully diversified, since on the international financial market the only asset traded is a riskless nominal bond. Households maximize the expected discounted utility flow:

$$
U^{j}=E_{0} \sum_{t=0}^{\infty} \beta^{t} U_{t}^{j}\left(C_{t}^{j}, N_{t}^{j}, \frac{M_{t}^{j}}{P_{t}}, D_{t}\right)
$$

subject to eq. (3) and the budget constraint:

$$
P_{t} C_{t}^{j}+M_{t}^{j}+e_{t} v_{t}^{*} B_{t}^{* j}++\vec{v}_{t} \vec{B}_{t}^{j} \leq W_{t}^{j} N_{t}^{j}+M_{t-1}^{j}+e_{t} B_{t-1}^{* j}+B_{t-1}^{j}+\Pi_{t}^{j}-\tau_{t}
$$

where $e_{t}$ is the nominal exchange rate, $v_{t}^{*}$ is the price of a zero-coupon riskless bond priced in foreign currency, $B_{t}^{*}$ is the amount of foreign asset purchased, $W_{t}$ is the wage rate, $\Pi^{j}$ is the share of profit from the monopolistic firms rebated to the household, and $\tau$ is a lump sum government tax. Each element of the row vector $\vec{v}_{t}$ represents the price of an asset that will pay one unit of currency in a particular state of nature in period $t+1$. The corresponding element of $\vec{B}_{t}$ represents the quantity of such claims purchased by the household. $B_{t-1}$ indicates the value of the household portfolio of claims against domestic residents given the current state of nature.

Households set the nominal wage $W^{j}$ in contracts which can be renegotiated with probability $\left(1-\theta_{w}\right)$. Of the households resetting the wage contract, a fraction $\left(1-\omega_{w}\right)$ updates the wage optimally, while a fraction $\omega_{w}$ follows a backward-looking rule of thumb. Eq. (4) and the index of aggregate employment $N_{t}=\int_{0}^{1} N_{t}(i) d i$ give household $j^{\prime}$ s downward sloping demand function for its type of labor:

$$
N_{t}^{j}=\left(\frac{W_{t}^{j}}{W_{t}}\right)^{-\phi} N_{t}
$$


As in the staggered wage adjustment model of Erceg et al. (1999) any household $j$ optimally resetting

the wage at time $t$ maximizes its utility functional with respect to the nominal wage $\tilde{W}_{t}^{j}$, subject to the sequence of budget constraints (eq. 8) and the labor demand function (eq. 9) at time $t+s$. We assume the rule of thumb adopted by a fraction $\omega_{w}$ of the wage-resetting households takes into account the average nominal wage, the CPI inflation rate and the average contract duration $\frac{1}{1-\theta_{w}}$, as in Rabanal (2001). Backward looking households update the wage to the average level prevalent across all contracts at time $t-1$, adjusted for the current inflation rate $\pi_{t}$ :

$$
W_{t}^{R T^{j}}=W_{t-1}\left(1+\pi_{t}\right)^{\frac{1}{1-\theta w}}
$$

For $\omega_{w} \rightarrow 0$ the model converges to the Erceg et al. (1999) wage-updating mechanism. This hybrid model implies aggregate nominal wage inflation depends explicitly on current and expected CPI inflation through the indexing rule (10).

\subsection{Import Sector}

We model incomplete pass-through of imported goods prices by assuming that the foreign-produced good $F$ is purchased by a continuum of monopolistically competitive firms in the import sector as an input for production (see Monacelli, 2005). Each firm $z$ can costlessly differentiate the imported good $X_{F}$ to produce a consumption good $C_{F}(z)$ using the production technology $Y_{F}(z)=X_{F}(z)$, where $X_{F}(z)$ denotes the amount of input imported by firm $z$. The nominal marginal cost of producing one unit of output is defined as $M C_{F, t}^{N}(z)=e_{t} P_{F, t}^{*}$ where $P_{F, t}^{*}$ is the foreign-currency price of $X_{F}$. The domestic-currency price $P_{F}(z)$ is set following the Calvo (1983) pricing model with a probability of price re-optimization equal to $\left(1-\theta_{F}\right)$. The producer faces an aggregate demand schedule given by:

$$
Y_{F, t}(z)=\left[\frac{P_{F, t}(z)}{P_{F, t}}\right]^{-\varrho} C_{F, t}
$$

where market clearing implies $Y_{F, t}(z)=C_{F, t}(z)$. This production structure generates deviations from the law of one price in the short run, while asymptotically the pass-through from the price of the imported good to the price of the consumption basket $F$ is complete. 


\subsection{Government Sector and Aggregate Shocks}

The government budget is balanced in every period $t$. The central bank monetary policy is described by the interest rate rule:

$$
\frac{\left(1+\bar{i}_{t}\right)}{\left(1+i^{s s}\right)}=\left[E_{t}\left(\frac{\Pi_{t+1}}{\Pi_{S S}}\right)\right]^{\omega_{\pi}}\left(\frac{Y_{H, t}}{Y_{H, S S}}\right)^{\omega_{y}}
$$

where $\omega_{\pi}, \omega_{y} \geq 0$ are the feedback coefficients to deviations of the expected gross CPI inflation rate

$\Pi_{t+1}=\frac{P_{t+1}}{P_{t}}$ and domestic output from their steady state values $\Pi_{S S}, Y_{H, S S}$. We assume the policymaker adjusts the interest rate only gradually to the target rate $\bar{i}_{t}$ :

$$
\left(1+i_{t}\right)=\left[\left(1+\bar{i}_{t}\right)\right]^{(1-\chi)}\left[\left(1+i_{t-1}\right)\right]^{\chi} \varepsilon_{i, t}
$$

where $\chi \in[0,1)$ is the degree of smoothing and the exogenous shock $\varepsilon_{i, t}$ represents non-systematic movements in the monetary policy instrument. The logarithm of the exogenous preference shock $D_{t}$, technology shock $A_{t}$, aggregate foreign demand $C_{t}^{*}$, and the world interest rate $\tilde{\imath}_{t}^{*}$ and imports' price inflation $P_{F, t}^{*} / P_{F, t-1}^{*}$ follow a first order autoregressive stochastic process, with random innovation $\varepsilon_{j, t} \sim N\left(0, \sigma_{j}^{2}\right)$. The exogenous policy shock $\varepsilon_{i, t}$ is assumed to have no serial correlation. Market clearing conditions and aggregate equilibrium conditions are in Appendix 7.6.

\section{Counterfactual Histories: Methodology}

Write the linearized DSGE model equilibrium law of motion as:

$$
\begin{aligned}
& \xi_{t+1}=F \xi_{t}+v_{t+1} \\
& q_{t}=H^{\prime} \xi_{t} \\
& { }^{n+m \times 1} \xi_{t}=\left[\begin{array}{c}
n \times 1 \\
{ }^{n \times 1} \xi_{t}^{1} \\
{ }^{2}
\end{array}\right]=\left[\begin{array}{c}
x_{t-1} \\
z_{t}
\end{array}\right] \\
& { }^{n+m \times 1} v_{t}=\left[\begin{array}{c}
{ }^{n \times 1} 0 \\
\\
m \times 1 \\
{ }^{2} \varepsilon_{t}
\end{array}\right] \\
& { }^{n+m \times n+m} F=\left[\begin{array}{cc}
{ }^{n \times n} F^{11} & n \times m \\
{ }^{m \times n} 0 & m \times m \\
{ }^{12} & { }^{22}
\end{array}\right] \\
& { }^{r \times n+m} H^{\prime}=\left[\begin{array}{ll}
{ }^{r \times n} H^{\prime 1} & r \times m \\
{ }^{\prime 2}
\end{array}\right]
\end{aligned}
$$




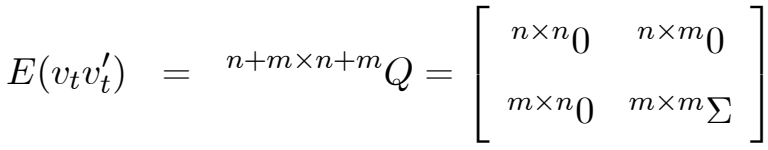

$$
\begin{aligned}
& E\left(v_{t} v_{\tau}^{\prime}\right)=[0] \quad \text { for } \tau \neq t
\end{aligned}
$$

$q_{t}$ is an $r \times 1$ vector of observable variables, which may include elements of both the endogenous state vector $x_{t}$ and control vector $y_{t} . \varepsilon_{t}$ is a multivariate Gaussian stochastic process with covariance matrix $\Sigma$ and unconditional expectation $E\left(\varepsilon_{t}\right)=0$. Capital letters denote matrices. The index in the upper-left corner indicates the size of a matrix.

The law of motion in eqs. (13), (14) can be inverted to obtain the vectors $\xi_{t}^{1}$ and $\xi_{t}^{2}$ conditional on a vector of observable variables $q_{t}$. Given an initial condition $\xi_{0}$ and matrices $F, H^{\prime}$ the state vector $\xi_{t}$ can be calculated from the recursion:

$$
\begin{aligned}
\xi_{t}^{1} & =F^{11} \xi_{t-1}^{1}+F^{12} \xi_{t-1}^{2} \\
\xi_{t}^{2} & =\left(H^{\prime 2}\right)^{-1}\left[q_{t}-H^{\prime 1} \xi_{t}^{1}\right]
\end{aligned}
$$

For $H^{\prime 2}$ to be invertible only $m$ out of the $r$ variables in the vector $q_{t}$ must be included. $\xi_{t}^{2}$ is the historical shocks vector consistent with the DSGE model and the observation vectors $\left[q_{1} \ldots q_{t}\right]$. Eq. (13) can be used to back out the corresponding series of innovations $\varepsilon_{t}$. We label this procedure the 'accounting approach'. Its mechanics imply that under the historical policy the model-simulated path for the observables conditional on the historical vector $\xi_{t}^{2}$ is identical to the data. Chari, Kehoe and McGrattan (2007) use the accounting approach to measure how much of the business cycle fluctuations can be explained by each shock during historical episodes ${ }^{6}$.

The accounting approach constrains the structural shocks to explain all of the variance observed in the data. We relax this assumption by assuming that the observable variables are described by the vector $q_{t}^{o}$ :

$$
q_{t}^{o}=q_{t}+w_{t}
$$

where $w_{t}$ is an $r \times 1$ Gaussian vector stochastic process with covariance matrix $R$ :

$$
E\left(w_{t} w_{t}^{\prime}\right)=R ; E\left(w_{t} w_{\tau}^{\prime}\right)=[0] \text { for } \tau \neq t ; \quad E\left(v_{t} w_{\tau}^{\prime}\right)=[0] \forall \tau
$$

\footnotetext{
${ }^{6}$ Chari, Kehoe and McGrattan's (2007) 'business cycle accounting' identifies time-varying wedges in the equilibrium decision-rules, rather than structural shocks, since the covariance matrix $\Sigma$ is not restricted to be diagonal. The authors show that a large class of models is equivalent to a prototype model with time-varying wedges.
} 
In the econometric literature $w_{t}$ is assumed to represent a measurement error vector. It can be interpreted as summarizing the volatility in $q_{t}^{o}$ which is not explained by the DSGE model. For the system defined by eqs. (13), (14) and (23), and given the assumptions in equations (15) to (20), (24) we define the linear projection of $\xi_{t+1}$ on the sample $\left[q_{1}^{o} \ldots q_{t}^{o}\right]$ and a constant as the Kalman filtered estimate $\xi_{t+1 \mid t}$ and $P_{t+1 \mid t}$ the associated mean squared error (MSE). The Kalman smoothed estimate $\xi_{t \mid T} \equiv \hat{E}\left(\xi_{t} \mid q_{1}^{o} \ldots q_{T}^{o}\right)$ of the vector $\xi_{t}$ is based on the full sample of observable variables, and $P_{t \mid T}$ is the associated MSE.

A counterfactual history $[\bar{q}]_{t=1}^{T}$ is built by simulating the model in eqs. (13) and (14) conditional on a counterfactual law of motion $\bar{F}^{11}, \bar{F}^{12}, \bar{H}^{\prime}$ and on the estimate $\left[\xi_{t \mid T}^{2}\right]_{t=1}^{T}$. Because the model includes the vector of disturbances $w_{t}$, simulation of the historical equilibrium law of motion $F, H^{\prime}$ conditional on the filtered structural shocks in $\varepsilon_{t}$ will not generate the historical data series. Part of the variance in the observable $q_{t}^{o}$ is accounted for by $w_{t}$, while the vector $\varepsilon_{t}$ (and the implied $\xi_{t}^{2}$ vector) only explains the variance of the unobservable $q_{t}$. Therefore any counterfactual history $\bar{q}_{t}$ by construction generates a counterfactual path for $q_{t}$ rather than $q_{t}^{o}$. The law of iterated projections implies that the Kalman smoothed estimate $q_{t \mid T} \equiv \hat{E}\left(q_{t} \mid q_{1}^{o} \ldots q_{T}^{o}\right)$ is equal to $H^{\prime} \xi_{t \mid T}$. The vector $q_{t \mid T}$ can be compared to the counterfactual $\bar{q}_{t}$ conditional on $\xi_{t+1 \mid T}^{2}$, which is computed as:

$$
\begin{aligned}
\bar{\xi}_{t+1} & \equiv\left[\begin{array}{c}
\bar{\xi}_{t+1}^{1} \\
\bar{\xi}_{t+1}^{2}
\end{array}\right]=\left[\begin{array}{cc}
\bar{F}^{11} & \bar{F}^{12} \\
0 & I
\end{array}\right]\left[\begin{array}{c}
\bar{\xi}_{t}^{1} \\
\xi_{t+1 \mid T}^{2}+\widetilde{\xi}_{t+1}^{2}
\end{array}\right] \\
\bar{q}_{t} & =\bar{H}_{t}^{\prime} \bar{\xi}_{t}
\end{aligned}
$$

where $\bar{F}^{11}, \bar{F}^{12}, \bar{H}^{\prime}$ describe the counterfactual law of motion and $\bar{\xi}_{t}$ describes the counterfactual path of the state variables. For $\widetilde{\xi}_{t}^{2}=0 \forall t$ the system in eqs. (25) and (26) simulates the economy dynamics when only the law of motion is changed. In some instances it is useful for some of the $\widetilde{\xi}_{t}^{2}$ components to be nonzero in order to build counterfactual histories conditional on alternative shocks series. Note that by construction this method uses only the DSGE model in building a counterfactual history, since all the variance in $q_{t \mid T}$ and $\bar{q}_{t}$ is explained by the model structural shocks. The vector $w_{t}$ enters in the estimation of these shocks. 


\section{The Impact of Inflation Targeting}

The building of the Kalman-filter counterfactuals proceeds as follows. First we estimate the monetary policy rule coefficients over the inflation targeting sample and over the earlier 1971-1990 sample using a GMM estimator. Then we use the Kalman filter to evaluate the likelihood function of the model in eqs. (13), (14) and (23) conditional on the GMM estimates over the inflation targeting sample. The maximum likelihood estimates are used to filter the historical shocks $\left[\xi_{t \mid T}^{2}\right]_{t=1}^{T}$ and to compute counterfactuals using eqs. (25) and (26) and the appropriate choice of $\bar{F}^{11}, \bar{F}^{12}, \bar{H}^{\prime}$. A detailed description of the data set and estimation procedure is contained in Appendices 7.1 and 7.2.

\subsection{Estimation}

\subsubsection{Monetary Policy Rule}

Canadian monetary policy in the period before and after the adoption of inflation targeting is estimated on quarterly data using a two-stage GMM estimator with heteroschedasticity and autocorrelation consistent covariance matrix. The orthogonality condition exploited in the GMM estimation is $E\left[i_{t}-\right.$ $\left.(1-\chi) \alpha-(1-\chi) \omega_{\pi} \pi_{t+1}-(1-\chi) \omega_{y} y_{t}-\chi i_{t-1} \mid u_{t}\right]=0$ where $\alpha$ is a constant and $u_{t}$ is the set of instruments. It is obtained by combining eqs. (11), (12) and taking a loglinear approximation around the steady state. The instruments set is similar to the one used by Clarida et al. (1998), and includes: four lags of the interest rate, inflation rate, money supply growth rate and three lags of the HodrickPrescott filtered output. Including lagged values of the real exchange rate among the regressors did not significantly modify the results.

The inflation targeting sample runs from 1992:1 to 2005:1. Inflation targeting was formally adopted in the first quarter of 1991, and the first target was set to reduce CPI inflation in the 1 to 3 percent range by the end of 1995, although inflation averaged $2 \%$ already in the first year. Before the announcement of specific inflation targets, the Bank of Canada had embarked in a three-year campaign to promote price stability as the long term objective of monetary policy, though it made little headway against the momentum in inflation expectations that had built up. In the fourth quarter of 1990 inflation was still at $4.2 \%$. The pre-inflation targeting sample on which $\omega_{\pi}, \omega_{y}, \chi, \alpha$ are estimated runs from 1971:1 (following the eight year period ending in 1970 when Canada pegged its exchange rate to the US dollar) to 1990:4. Table 1 reports the estimates, showing that in the inflation targeting period the weight on expected inflation increased from 1.09 to 2.16, while the weight on the HP-filtered output measure dropped from 1.21 to 0.27 . The estimate of the coefficient $\chi$ on lagged interest rate 
remained very high across subsamples. All estimated coefficients are significant at least at the $5 \%$ confidence level.

\subsubsection{Maximum Likelihood Estimation}

We estimate the small open economy model using a maximum likelihood estimator as in Bergin (2003) and Ireland (2004). The object of the estimation is the state-space representation of the loglinear approximation to the DSGE model law of motion, as specified in eqs. (13), (14) and (23). The likelihood function for the sample $\left[q_{t}^{o}\right]_{t=1}^{T}$ can be constructed using the Kalman filter, and depends nonlinearly on the structural parameters. The Sims (1999) algorithm is used to search for values of the DSGE model parameters and of the matrix $R$ that will maximize the likelihood function.

The DSGE model parameters are estimated over the 1991:1 to 2007:2 sample using the observed data vector for 10 variables:

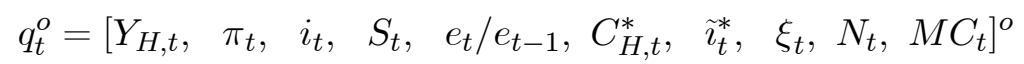

where the $o$ superscript indicates that the observation available for variable $x_{j, t}$ is given by $x_{j, t}^{o}=x_{j, t}+$ $w_{j, t}$. The output variable $Y_{H, t}$ is measured by the sum of constant-price consumption and net exports, consistent with the model definition of output that includes only domestic and foreign consumption of the home produced good: $Y_{H, t}=C_{H, t}+C_{H, t}^{*}$. Canadian real GDP over the same sample is about $20 \%$ less volatile, and shows a very similar pattern of correlations with the other macroeconomic aggregates. The inflation measure $\pi_{t}$ is the seasonally adjusted CPI net of indirect taxes. The interest rate $i_{t}$ is the 3 -month T-bill rate, although nearly identical results are obtained with the overnight rate. The terms of trade series $S_{t}=P_{F, t} / P_{H, t}$ is the ratio of the Laspeyres index for import and export prices. Nominal exchange rate depreciation $e_{t} / e_{t-1}$ is obtained from the Canadian/US dollar exchange rate (trade with the US accounts for about $80 \%$ of total Canadian international trade). The exports series $C_{H, t}^{*}$ is given by the Canadian constant-price export index for goods and services. The foreign interest rate $\tilde{\imath}_{t}^{*}$ is the US 3 -month T-Bill quarterly yield. Nominal wage inflation $\xi_{t}$ is measured by the average hourly earnings for the non-farm sector, including government but excluding the defense and not-for-profit sectors. The series for total labor hours $N_{t}$ is built using employment and average weekly hours of the same non-farm sector. The real marginal cost $M C_{t}$ is obtained from the unit labor cost series for the business sector discounted by the appropriate price deflator. All series are measured as log-deviations from the steady state, except for $Y_{H, t}, C_{H, t}^{*}, N_{t}$ and $M C_{t}$ which are logged 
and Hodrick-Prescott filtered. ${ }^{7}$

The covariance matrix $R$ for the shocks vector:

$$
w_{t}=\left[w_{Y_{H, t}}, w_{\pi_{t}}, w_{i_{t}}, w_{S_{t}}, w_{e_{t} / e_{t-1}}, w_{C_{H, t}^{*}}, w_{\tilde{\imath}_{t}^{*}}, w_{\xi_{t}}, w_{N_{t}}, w_{M C_{t}}\right]
$$

is assumed to be diagonal. Ireland (2004) suggests a more flexible specification, allowing for a VAR structure of the $w_{t}$ components. We experimented with this specification, but the ML estimates of the VAR coefficients and cross-correlations were for the large part not significant, while the robustness of the search algorithm to the initial starting value decreased considerably. The covariance matrix $\Sigma$ of the structural shocks innovations is assumed diagonal, except for the submatrix describing the covariances for the foreign shocks $C_{t}^{*}, \tilde{\imath}_{t}^{*}$ and $P_{F, t}^{*} / P_{F, t-1}^{*}$. The non-zero correlation across these shocks allows the model to generate a richer dynamics for the foreign sector, and at the same time is a more parsimonious specification than a full blown VAR system.

The variance of the $w_{t}$ disturbance for $\tilde{\imath}_{t}^{*}$ cannot be separately identified from the variance of the shock itself, and we constrain the corresponding element in the $R$ matrix to be zero. We also constrain to zero the variance of the $w_{t}$ disturbance for $i_{t}$ which cannot be separately identified from the variance of the policy shock $\varepsilon_{i, t}$. The parameters $\eta$ and $\phi$ are not identified. To estimate $\eta$, the inverse of the steady state labor supply elasticity, the value of the steady state wage markup $\phi /(\phi-1)$ is assumed equal to $10 \%$, implying $\phi=11$. Amato and Laubach (1999) estimate a sticky price/sticky wage model of the US economy and find a value of $\phi$ equal to 8.5 with a standard deviation of 6.1. We use the model's steady state restrictions to set prior to estimation some additional parameters for which the data contain only limited information. The quarterly discount factor $\beta$ is set to 0.99 , which implies a steady state real world interest rate of 4 percent. The foreign good share $\gamma$ is equal to the steady state ratio between imports and domestic output, and is set to 0.35 , the average Canadian import/output ratio over the inflation targeting sample. Finally, the elasticity of substitution between domestic goods $\vartheta$ is set equal to 6 , so that the markup in a flexible-price steady state is $20 \%$ (Gali and Monacelli, 2005).

Parameter Estimates ML estimates and standard errors for 30 parameters are reported in Table 2. Most of the parameters are estimated with a low level of uncertainty, including the elements of the covariance matrix $R$. The estimate of the standard deviations for the $w_{t}$ vector components is

\footnotetext{
${ }^{7}$ We chose to filter also the series for $M C_{t}$ since it is characterized by a strong downward trend throughout the inflation targeting period that the DSGE model is not built to explain.
} 
of the same order of magnitude as the volatility estimate for some of the structural shocks in $\xi_{t}^{2}$. This suggests there are important features in the data that the DSGE model propagation mechanism cannot account for. The standard deviation of the preference shock innovation is $\sigma_{d}=5.68$. This value is large compared to the other disturbances, but it is not unusual for models with nominal rigidities to require volatile shocks to fit aggregate data. Rabanal and Rubio Ramirez (2005) estimation of a sticky price/sticky wage model on US data yields a standard deviation of the taste shock twice as large $\left(\sigma_{d}=11.88\right)$. Del Negro et al. (2006) estimate a preference shock standard deviation of 40.54 within a large-scale New Keynesian model of the US economy. Hall's (1997) empirical decomposition shows that most of the volatility in U.S. labor hours can be attributed to a preference shift between market and non-market activities, and is consistent with the empirical evidence in Eichenbaum, Hansen and Singleton (1988) on the co-movements of real wages, consumption and work effort.

The estimates for the price and wage setting parameters deserve an extended comment. The estimates for $\theta_{w}$ imply an average wage contract duration of five quarters, with about two thirds of the contracts being reset at the optimal wage. The average length of wage settlements in Canada over the 1991-2000 period is 29.77 months (Longworth, 2002), but this figure does not include contracts in the non-unionized sector, and worker's unionization in Canada has been declining. Additionally, the estimate for $\theta_{w}$ implies a measure for the interval between wage adjustment, rather than the interval between contract renegotiations.

The estimate for $\theta_{F}$ implies an average price duration for imported good of 3.75 quarters. The estimate of the price setting probability $\theta_{p}$ for the domestic production sector implies an implausibly long average price duration of 16 quarters. In addition, a fraction $\omega_{p}$ close to 0.9 of the prices are adjusted according to rule of thumb behaviour. When estimating DSGE model on aggregate US postwar data, other authors have obtained estimates in the $0.85-0.9$ range for $\theta_{p}$ and in the $0.82-0.96$ range for the degree of indexation to past prices among the non-reoptimizing firms (Rabanal and Rubio-Ramirez, 2005, Smets and Wouters, 2005). A comparison with the full-indexation price updating mechanism in Chistiano et al. (2005) is useful to illustrate the implications of the ML estimated parameters. These authors assume that a fraction of the firms can reset the price to the optimal level, while the remaining fraction indexes to lagged CPI inflation. Given the timing assumptions, the loglinear equilibrium condition for inflation is:

$$
\pi_{H, t}=\gamma_{b}^{*} \pi_{H, t-1}+\gamma_{f}^{*} E_{t-1} \pi_{H, t+1}+\frac{\left(1-\beta \theta_{p}\right)\left(1-\theta_{p}\right)}{(1+\beta) \theta_{p}} E_{t-1} m c_{t}
$$




$$
\gamma_{b}^{*}=\frac{1}{1+\beta} \quad ; \quad \gamma_{f}^{*}=\frac{\beta}{1+\beta}
$$

where lower case letters indicate log-deviations from the steady state. Since any plausible parameterization for $\beta$ implies a value close to 1 to be consistent with estimates of the steady state real interest rate, the Christiano et al. (2005) inflation equation necessarily assigns nearly identical weights $\gamma_{b}^{*}$ and $\gamma_{f}^{*}$ to lagged and expected inflation, and a weight whose value is close to $1 / 2$. The Gali and Gertler (1999) rule-of-thumb price resetting mechanism we adopt results in the loglinear equilibrium condition:

$$
\begin{aligned}
\pi_{H, t} & =\gamma_{b} \pi_{H, t-1}+\gamma_{f} E_{t} \pi_{H, t+1}+\frac{(1-\omega)\left(1-\theta_{p}\right)\left(1-\beta \theta_{p}\right)}{\Psi} m c_{t} \\
\gamma_{b} & =\frac{\omega}{\Psi} ; \gamma_{f}=\frac{\beta \theta_{p}}{\Psi} ; \Psi=\theta_{p}+\omega\left[1-\theta_{p}(1-\beta)\right]
\end{aligned}
$$

The estimates in table 2 imply $\gamma_{b}=0.49$ and $\gamma_{f}=0.51$, that is coefficients on lagged and expected inflation that are virtually identical to the ones that appear in the price indexation model (27). Therefore both price updating mechanisms generate similar reduced form dynamics for inflation. But to be consistent with the reduced form favored by the data, both the rule of thumb model and the price indexation model imply an average price duration inconsistent with the microeconomic evidence, too long for the first one (16 quarters), too short for the second one (1 quarter). We interpret this result as evidence that neither of the two price resetting mechanism can be considered fully structural.

Likelihood Ratio Tests We use the likelihood ratio to compare the fit of the estimated model to a state-space model where none of the DSGE restrictions is imposed. This is a strategy used by Bergin (2003) to evaluate the performance of the estimated model against an unrestricted model which takes the same reduced form, and therefore nests the DSGE model.

Estimation of the unrestricted model involves finding a parameterization for the matrices $F, H, Q, R$ that maximizes the likelihood function. Since none of the DSGE model cross-equation restrictions is imposed, the unconstrained model is bound to have a higher likelihood than the constrained DSGE model. The likelihood ratio test evaluates the statistical significance of the improvement in likelihood obtained by removing the DSGE model restrictions. The test accounts for the degrees of freedom, equal to the number of entries in $F, H$ and in the lower triangular portion of the covariance matrices $Q, R$, minus the number of estimated parameters in the restricted model. Results are reported in table 3. The test cannot reject the DSGE model restrictions, the p-value of the null hypothesis being 
equal to 0.23 .

The result that the unconstrained model does not perform significantly better compared to the hybrid DSGE model is in part to be attributed to the degrees of freedom allowed by the additional vector of disturbances $w_{t}$. The relevance of the $w_{t}$ vector can be evaluated comparing the estimated DSGE model to a model where the variance of (some components of) $w_{t}$ is set to zero. Since the model has only six structural shocks, at least four components of $w_{t}$ must have non-zero variance to avoid stochastic singularity when estimating the model over the 10 -variables data set. Table 3 shows the likelihood ratio test result when the non-zero variance components of $w_{t}$ are $\left[w_{S_{t}}, w_{e_{t} / e_{t-1}}, w_{\xi_{t}}, w_{N_{t}}\right]$. The zero-variance restrictions on the matrix $R$ can be rejected at any significance level. Any other choice of zero-variance restriction results in an even lower likelihood.

The likelihood ratio can also be used to evaluate the role of nominal rigidities in the model performance. Table 3 provides the likelihood ratio for the restricted model where domestic wages and prices are reset optimally in every period (the parameters $\theta_{p}, \theta_{w}, \omega_{p}, \omega_{w}$ are restricted to be equal to zero) and the benchmark hybrid model. The restrictions are rejected, implying that nominal rigidities play a statistically significant role in fitting the data. Finally, we test separately for the significance of the nominal rigidity in the foreign good import sector. This test is meant to discriminate between the producer and consumer currency-pricing hypothesis for the imported good. A value of $\theta_{F}=0$ implies instantaneous, complete pass-though of foreign price movements. This restriction can be rejected at any level of significance, as shown in the last line of table 3.

\subsubsection{Structural Shocks Estimate}

The Kalman-smoothed estimate of the structural shocks over the 1991:1-2007:2 sample is in figure 1, together with \pm 1 root mean square error (RMSE) bands. The foreign interest rate shock $\tilde{\imath}_{t}^{*}$ has no RMSE band since is included among the observables. We assume no prior information is available at time $t=0$, and the recursion starts with $\xi_{1 \mid 0}=E\left(\xi_{1}\right)$ and $P_{1 \mid 0}=E\left\{\left[\xi_{1}-E\left(\xi_{1}\right)\right]\left[\xi_{1}-E\left(\xi_{1}\right)\right]^{\prime}\right\}$.

The technology disturbance is on average negative until 1994, then takes both negative and positive values throughout the remaining sample. This behaviour is not at odds with the strong Canadian output expansion in the 1990s. It is consistent with the Hodrick-Prescott filtered series for output used in the estimation, and with output gap estimates published by the Bank of Canada in its Monetary Policy Report, which imply an increase in both output and potential output in this period. Up to 1995 the data also imply a large and persistently negative preference shock, contributing to the severity of the recession in the early 1990s. The preference shock is mostly negative throughout the 
1990s, possibly proxing for the fiscal consolidation during part of the decade. The monetary policy shock is small over all the sample. The estimates indicate that policy shocks were more volatile in the early years of inflation targeting, while in the 2000 to 2002 period the monetary authority set lower interest rates then warranted by the policy rule.

Figure 2 plots the historical data together with the smoothed estimate $q_{t \mid T}$ for the variables $Y_{H, t}, i_{t}, S_{t}, C_{H, t}^{*}{ }^{8}$. The \pm 1 RMSE error bands for $q_{t \mid T}$ are computed from $M S E_{q_{t \mid T}} \equiv E\left\{\left[q_{t}-q_{t \mid T}\right]\left[q_{t}-\right.\right.$ $\left.\left.q_{t \mid T}\right]^{\prime}\right\}=H^{\prime} P_{t \mid T} H+R$.

\subsection{The Luck Hypothesis and the Cost of Inflation Targeting}

The first thought experiment compares the smoothed estimate of the historical annual CPI inflation $\pi_{t \mid T}$ with the counterfactual path $\bar{\pi}_{t}$ under the hypothesis that inflation targeting had not been adopted in 1991 (figure 3). It assumes $\bar{\xi}_{t}^{2}=\xi_{t \mid T}^{2}$ and that $\bar{F}^{11}, \bar{F}^{12}, \bar{H}^{\prime}$ are computed conditional on the estimated pre-inflation targeting policy rule. We assume identical long-term inflation goals under the two regimes.

Table 4 reports statistics to compare the two sample paths. The second row of table 4 shows that inflation targeting did not lower the realized volatility of inflation in the $1991-2007$ period. What is remarkable is that while the volatility of inflation is virtually identical under the two policies conditional on the Kalman-smoothed shocks vector $\xi_{t \mid T}^{2}$ for the sample, the population volatility computed from the ML estimate of the shocks' covariance matrix $\widehat{Q}$ is more than $60 \%$ higher under the counterfactual policy than in the inflation targeting regime. In other words, the historical shock vector was such that the policy rule had no impact on inflation volatility, even if ex-ante we would expect a change in inflation volatility.

Even if it did not affect significantly the volatility, the inflation targeting policy may still have had an important impact on the sample level of inflation, contributing to keeping it low. The last two rows of table 4 illustrate this point. Over the whole sample, inflation would have been on average $40 \%$ higher under the counterfactual policy. The level increase is even larger for the period following 2003. Since the average level of inflation is low, a $40 \%$ increase in inflation translates in an average inflation differential between the counterfactual and historical level of only 0.43 percentage points.

The Bank of Canada success in reducing inflation was associated by some critics with a high cost in terms of unemployment (Fortin, 1996). But it is by no means clear that the $10 \%$ unemployment rate reached in the early 1990s could be avoided using a different monetary policy (Mishkin and Posen,

\footnotetext{
${ }^{8}$ If the estimate for $q_{t}$ is computed from the Kalman filtered series $\xi_{t \mid t-1}$, rather than the Kalman smoothed series $\xi_{t \mid T}$, the estimate $q_{t \mid t-1}$ has the interpretation of a forecast and is equal to the forecast $q_{t \mid t-1}^{o}$ since $E_{t-1}\left(w_{t}\right)=0$.
} 
1997). In the same period world oil markets created inflationary pressures, while low commodity prices harmed Canadian exports. The output counterfactual (figure 3) shows the inflation targeting policy imposed a substantial cost in the period 1992-1994, when the extra output loss averaged slightly less than $0.5 \%$ of trend output per quarter.

Overall, it appears that monetary policy was largely irrelevant for inflation volatility, and helped to keep the inflation level lower after 2003. To assess the luck hypothesis, the appropriate question to ask is how likely a path of inflation as observed in the counterfactual history would have been under inflation targeting. To this end, we use the DSGE model to evaluate the probability of observing a given range of (smoothed) inflation values in any time $t$ conditional on inflation targeting. Figure 3 plots the inflation unconditional 0.84 standard deviations bound above the mean computed from simulating the DSGE model under inflation targeting. Since the vector $q_{t}$ has a multivariate normal distribution, in the ergodic state $80 \%$ of the $\pi_{t}$ realizations will fall below the 0.84 standard deviations bound. The counterfactual inflation path lies above the 0.84 standard deviations bound in 15 periods over the sample. Yet in a long enough sample, inflation realizations as large as desired will occur even conditional on inflation targeting. Table 5 reports the results of a Monte Carlo exercise computing the probability of observing a given number $n$ of inflation realizations above the $80 \%$ probability bound for the inflation targeting policy-maker over a sample as long as the 1991 to 2007 period. Would chance alone allow the economy to experience the performance of the non-inflation targeting policy - as many as 15 inflation observations above the $80 \%$ probability bound over 66 quarters? This event would not be unlikely at all: it would occur with a probability of 0.38 . Even to generate the 9 consecutive inflation observation above the 0.84 standard deviations bound, as occurs in the counterfactual experiment between 2000:1 and 2002:1, the inflation-targeting central bank would not need much bad luck: such an event would be observed in $35 \%$ of the samples.

Since the shift to inflation targeting does generate a large decrease in the expected inflation volatility, what drives the result that in the sample the inflation behaviour is similar regardless of the monetary regime? After 1991 the estimated weights on the two variables entering the monetary reaction function, $\pi$ and $y$, change in opposite directions. As a consequence, shocks that result in the model in a high negative correlation between inflation and output have the largest impact on the behaviour of policy, and ultimately on the counterfactual inflation time series. Table 6 shows the correlation between inflation and output in a hypothetical Canadian economy where all the business cycle volatility were generated by a single shock. Technology, preference and foreign demand shocks generate a very high negative correlation. If these shocks play a sufficiently large role in explaining the inflation volatility, 
we would expect the counterfactual inflation time series to be strongly affected by the change in policy. 9 This is the case in the estimated model, where inflation volatility under the counterfactual policy is more than $60 \%$ higher than in the inflation targeting regime when computed from the ML estimate of the shocks' covariance matrix $Q$. Using the ML estimate $\widehat{Q}$, the forecast error variance explained by the shocks $\tilde{\imath}_{t}^{*}, P_{F, t}^{*} / P_{F, t-1}^{*}, \varepsilon_{i_{t}}$ - that do not generate a strong negative correlation for inflation and output - is between $77 \%$ and $79 \%$. In the 1991:1 to 2007:2 sample, where the sample covariance matrix across the shocks is $\widehat{\widehat{Q}}=\frac{1}{T} \Sigma_{t=1}^{T} \widehat{v}_{t} \widehat{v}_{t}^{\prime}$, the variance explained by the same shocks is for most orthogonalizations above $90 \% .{ }^{10}$ As a consequence, a change in the policy rule has a smaller than expected impact on the inflation time series over the sample. Had, for example, the technology or preference shock played a larger role in explaining the inflation behaviour over the sample, the shift to inflation targeting would have resulted in a larger divergence between the historical and counterfactual inflation path.

Obviously the inflation behaviour results are also dependent on the parameter estimates. The estimates for $\theta_{p}$ and $\omega_{p}$ in the price-adjustment equation imply inflation is very inertial, and could potentially limit the sensitivity of inflation to the policy rule. Table 4 shows that the large share of rule-of-thumb firms has only a small impact on the result. In an economy with no rule-of-thumb firms (implying $\gamma_{b}=0$ and $\gamma_{f}=0.99$ in eq. 28) the counterfactual policy would have implied an increase in inflation volatility of only $8 \%$. Finally, it is legitimate to ask whether, given the Kalman-filtered shocks vector $\xi_{t \mid T}^{2}$, the DSGE model is able to generate higher inflation volatility at all. This is indeed the case. Table 4 includes the result from the counterfactual experiment conducted in an economy with a higher steady-state labor supply elasticity $1 / \eta$, increasing from 0.38 to 1 . In this economy the sample volatility would increase more than twofold relative to the inflation targeting policy case. ${ }^{11}$

In summary, the estimation shows that the inflation path under the earlier monetary policy would have had a high likelihood of being generated also by an inflation targeting monetary policy. Chance alone resulted in a lower volatility of inflation over the period.

\footnotetext{
${ }^{9}$ This statement is not necessarily true in a DSGE model, since the correlation between inflation and output is endogenous to the choice of policy. For the estimated model though the statement is accurate.

${ }^{10}$ Since the estimation imposes overidentifying restrictions, the ML estimate $\widehat{Q}$ can differ from the covariance matrix of the sample shocks $\frac{1}{T} \Sigma_{t=1}^{T} \widehat{v}_{t} \widehat{v}_{t}^{\prime}$. Note that since the covariance matrix is not diagonal, the fraction of inflation variance attributable to each innovation depends on their order of preference. We assume foreign shocks are exogenous from Canada's point of view, while Canadian shocks do not affect the rest of the world. The ordering of the domestic shocks does not alter the outcome of the variance decomposition exercise, and these results are not reported.

${ }^{11}$ This result is provided to show that there exist model parameterizations which can imply a large impact of policy on inflation volatility conditional on the estimated sample shocks vector. It does not imply that the result on the impact of inflation targeting is extremely sensitive to the estimated parameters, since for different parameter estimates the Kalman-smoothed shocks vector would be different as well.
} 


\subsection{The Impact of Policy Shocks}

The second counterfactual examines the impact of policy shocks in Canada by simulating an economy conditional on the inflation targeting policy but setting to zero the monetary policy disturbance (figure 4). The counterfactual assumes $\bar{F}^{11}=F^{11}, \bar{F}^{12}=F^{12}, \bar{H}^{\prime}=H^{\prime}$. We set the $j^{\text {th }}$ component of the

vector $\widetilde{\xi}_{t}^{2}$, corresponding to the policy shock $\varepsilon_{i, t}$, equal to $-\xi_{t \mid T}^{2^{j}}$ so that $\bar{\xi}_{t}^{2^{j}}=0 \forall t$. The vector composed of all the elements of $\bar{\xi}_{t}^{2}$ except the $j^{t h}$ one, $\bar{\xi}_{t}^{2^{-j}}$, is unchanged and equal to $\xi_{t \mid T}^{2^{-j}}$.

The impact of policy shocks on inflation is limited over the sample, of the order of a quarter of a percentage point. Unexpected movements in monetary policy played a more important role in output dynamics. By lowering the interest rate level, they contributed to keeping output above trend over the 2002-2005 period. The improvement in output is as high as $1 \%$. The counterfactuals show that the non-systematic component of monetary policy did not carry any weight for the poor output performance in the early 1990s.

\subsection{The Impact of Credibility}

Central banks adopting inflation targeting frameworks consider the achieved macroeconomic stability, at least in part, a result of the increased credibility of the policy commitment to inflation stabilization. Some authors (see Kuttner and Posen, 1999) argue instead that the adoption of inflation targeting simply indicates the central bank's shift towards a greater conservatism with respect to the inflation goal, with increased credibility and transparency playing a minor role for the policy's outcome.

The third counterfactual evaluates the role of the inflation targeting credibility in Canadian's inflation performance since 1991 by building a history under the assumption that the shift in monetary policy occurred but was not believed by the private sector (figure 5). It assumes $\bar{\xi}_{t}^{2}=\xi_{t \mid T}^{2}$. The matrices $\bar{F}^{11}, \bar{F}^{12}, \bar{H}^{\prime}$ are built under the hypothesis that the monetary authority adjusts interest rates according to the estimated post-1991 inflation targeting policy $\left(\bar{F}^{11}=F^{11}, \bar{F}^{12}=F^{12}, \bar{H}^{\prime}=H^{\prime}\right)$, while the private sector expectation $\widetilde{E}_{t}^{p s}\left[s_{t+1}\right]$ of any variable $s_{t}$ is conditioned on the belief the central bank adopts the policy rule estimated for the earlier period. Thus, while the actual policy changes relative to the pre-inflation targeting period, the perceived policy used to form the private sector's expectation is unchanged. Effectively, the private sector interprets as non-systematic movements in the interest rate $\varepsilon_{i, t}^{p s}$ what truly is the sum of a policy shock and the distance between the interest rate implied by 
the true and believed policy rule:

$$
\begin{aligned}
i_{t}-\left\{\left(1-\chi^{p s}\right)\left[\omega_{\pi}^{p s} \widetilde{E}_{t}^{p s} \pi_{t+1}+\omega_{y}^{p s} y_{t}\right]+\chi^{p s} i_{t-1}\right\}= & \varepsilon_{i, t}^{p s} \\
= & \varepsilon_{i, t}+\left(\chi^{c b}-\chi^{p}\right) i_{t-1} \\
& +\left[\left(1-\chi^{c b}\right) \omega_{y}^{c b}-\left(1-\chi^{p s}\right) \omega_{y}^{p s}\right] y_{t} \\
& +\left[\left(1-\chi^{c b}\right) \omega_{\pi}^{c b} E_{t}^{c b} \pi_{t+1}-\left(1-\chi^{p s}\right) \omega_{\pi}^{p s} \widetilde{E}_{t}^{p s} \pi_{t+1}\right]
\end{aligned}
$$

where the index $p s$ indicates the private sector believes, the index $c b$ indicates the true value of a parameter in the central bank policy rule, and we assume the central bank's expectation of inflation is model-consistent: $E_{t}^{c b} \pi_{t+1}=E_{t} \pi_{t+1}$. Appendix 7.4 describes the equilibrium concept adopted to solve the DSGE model when the private sector holds incorrect believes.

Figure 5 shows that despite the monetary authority increased aggressiveness towards inflation, a non-credible policy would achieve an inflation path very close to the one under the assumption inflation targeting had not been introduced at all (shown in figure 3), that is, under a less inflation-averse, but fully credible policy. By and large, the experiment shows that whatever change in inflation dynamics occurred over the inflation targeting period must be attributed to the change in the perceived policy. At the same time, the non-credible inflation targeting regime would not lead to as large a stabilization of output as the credible non-inflation targeting regime. The counterfactual shows that conditional on the shocks vector the largest part of the change in inflation dynamics after 1991 originated from the expectation channel: the private sector adjusting its behaviour given the belief that the central bank's stance against inflation has become more aggressive.

To measure the gain from the expectation channel, we build a fourth counterfactual assuming the monetary authority still follows the inflation targeting policy without being believed by the private sector - but at each time $t$ adjusts the nominal interest rate to bring inflation to its historical level (figure 5). The counterfactual assumes the same matrices $\bar{F}^{11}, \bar{F}^{12}, \bar{H}^{\prime}$ as in the previous exercise while $\widetilde{\xi}_{t}^{2^{j}}$ is computed to ensure $\bar{\pi}_{t}=\pi_{t}$. Appendix 7.5 provides the recursion to build the appropriate $\bar{\xi}_{t}^{2^{j}}$. The counterfactual history describes an economy where the central bank achieves the given historical inflation path by actually changing the path of the interest rate through surprise policy interventions, rather than relying on its commitment to a policy rule to adjust the interest rate in response to the state of the economy.

Figure 5 shows the implied path of output. After 1996, output decreases persistently and dramatically. In the counterfactual, when faced with inflationary shocks the monetary authority raises 
interest rates and forces the economy into a severe recession to be able to achieve the inflation target path. Firms' expect policy to be more accommodative towards inflation than it really is, and the incorrect believes would lead firms to set persistently higher prices, ceteris paribus. The central bank reacts with unexpected increases in the nominal interest rate, that translate in real interest rate increases, to curb demand and the firms' inflationary behaviour. Because only $6 \%$ of the prices are updated in every period, incorrect believes are very persistent in the economy, and result in a prolonged recession.

The distance between the historical and counterfactual output represents the gain from credibility: the extra movement in output relative to the one a credible central bank, achieving the same inflation rate, would have experienced. Ex-ante, the distance can be positive or negative, depending on the combination of shocks hitting the economy. Given the Kalman-smoothed shocks, it leads to a prolonged recession in the sample.

\subsection{Alternative Methods to Build Counterfactuals}

Figure 6 compares the baseline Kalman filtering method to two alternative methodologies to build a counterfactual inflation series conditional on the pre-inflation targeting policy. The top panel plots the result from an exercise closer to the accounting approach. The shocks vector $\xi_{t \mid T}^{2}$ is Kalman-filtered using the DSGE model estimates in table 2 but assuming the only non-zero variance components of $w_{t}$ are $\left[w_{S_{t}}, w_{e_{t} / e_{t-1}}, w_{\xi_{t}}, w_{N_{t}}\right]$. This assumption allows using the same 10 data series to filter shocks as in the benchmark model. This fifth counterfactual is then obtained from the recursion in eqs. (21) and (22) assuming $\bar{F}^{11}, \bar{F}^{12}, \bar{H}^{\prime}$ are built conditional on the estimated pre-inflation targeting policy rule. The accounting method implies a shocks vector $\bar{\xi}_{t}^{2}$ with a larger variance, and this in turn returns a counterfactual path for inflation which is much more volatile than the counterfactual smoothed estimate of inflation in figure 3. By construction, the Kalman filter methodology returns a more conservative counterfactual path since a larger portion of the data volatility is explained by the vector $w_{t}$. At the same time, since the volatility of the unobserved component $w_{\pi_{t}}$ is constrained to 0 in this exercise, the counterfactual path must be compared to the observed historical path $\pi_{t}^{o}$ - which has a comparatively higher variance than the smoothed estimate $\pi_{t}$. Nevertheless, the accounting method would imply a very substantial impact of the monetary policy shift on inflation dynamics. Over the whole sample, inflation volatility would increase by $59 \%$ relative to the historical volatility. The full-fledged Kalmansmoothed counterfactual implied an increase of only $1 \%$.

The bottom panel of figure 6 still relies on the DSGE model, but shows a counterfactual

close in method to the VAR approach. The sixth counterfactual assumes $\bar{\xi}_{t}^{2}=\xi_{t \mid T}^{2}$. The matrices 
$\bar{F}^{11}, \bar{F}^{12}, \bar{H}^{\prime}$ are built under the hypothesis that the monetary authority adjusts interest rates according to the estimated pre-1991 policy, while the private sector believes the inflation targeting policy is being implemented. The solution method for the DSGE model law of motion is the same as the one used to evaluate the role of credibility. As in the VAR approach, the monetary authority changes its policy in the counterfactual, but this change is not allowed to affect the private sector's expectations. This methodology implies that counterfactual inflation would have followed very closely the historical path, the maximum distance being less than $0.2 \%$ in any period - and that inflation targeting played virtually no role in stabilizing inflation.

\section{Conclusions}

Industrial countries over the last two decades have experienced lower and more stable inflation - in some countries, as the US, together with increased output stability. This paper considers the inflation performance of an early and successful inflation targeter, Canada, to investigate whether the recent period of inflation stability can be explained by good luck - a favorable combination of business cycle shocks - rather than by the shift in the management of monetary policy

Contrary to a vast literature on the impact of inflation targeting, our estimates show that with a high probability good luck can explain the low inflation volatility throughout the inflation targeting period in Canada. The inflation targeting policy could, with a high probability of $35 \%$, have resulted in an inflation path as volatile as the one generated by the pre-inflation targeting policymaker conditional on the estimated business cycle shocks for the sample. We do not interpret the evidence for the luck hypothesis as implying that monetary policymaking is irrelevant: simply, inflation targeting has not been put to test by shocks generating a large enough trade-off for the policymaker. The counterfactual is built from an estimated DSGE model which predicts a much lower variance of inflation under inflation targeting, implying the inflation realizations generated by the counterfactual economy are ex-ante an unlikely event. Our estimates identify the larger than average weight of innovations in imported goods' inflation, domestic interest rates and foreign interest rates in explaining CPI inflation volatility over the inflation targeting period as driving the luck hypothesis result. At the same time, the introduction of inflation targeting may have played an important role in lowering average inflation by anchoring long term expectations, an issue that is clearly of utmost importance but cannot be addressed by our estimation exercise.

We introduce a method to evaluate the impact of policy announcements' credibility, and show 
that the inflation stabilization after 1991 is accounted for the most part by the credible announcement of an inflation target (a shift in the perceived policy) rather than by the change in the behaviour of the interest rate (a shift in the actual policy). We show that a non-credible inflation targeting policy that stabilized inflation at its historical level would have generated a prolonged recession. This result supports the claim that changes in policy regime can dramatically affect the economy dynamics by altering private agents' decision making (Sargent, 1999).

We obtain our results by Kalman-filtering the historical vector of structural disturbances from a maximum likelihood-estimated DSGE model. We provide a comparison with alternative methodologies to build counterfactual histories and show that forcing the DSGE model to explain all the volatility in the data would overturn the result from the counterfactual exercise, while neglecting the policy impact on expectations - as in the literature using reduced-form VAR models - would bias downward the impact of inflation targeting.

The drawback of using a structural model to build counterfactuals is reliance on strong assumptions on the economy's shocks propagation mechanism. The DSGE model provides the lens through which the data are read to filter the historical shocks series, and the law of motion to build counterfactuals. Yet our estimation allows the data, rather than exogenous assumptions, to select the appropriate model among a number of competing candidates. The estimated model encompasses, for example, economies with a complete pass-through import sector, RBC flexible-prices economies (where alternative monetary policies would be irrelevant), and economies with backward-looking final goods' pricing (where the impact of credibility would be greatly diminished). Finally, while the building of a counterfactual history wholly depends on the internal working of the DSGE model, the hybrid model approach helps mitigating potential model mis-specification in filtering the shocks. The question of how to assess policy changes ensuring robustness to a wider range of modeling assumptions is open for future research.

\section{References}

[1] Ahmed, S., Levin, A. and Wilson, A., (2004), 'Recent US Macroeconomic Stability: Good Policies, Good Practices or Good Luck?', Review of Economics and Statistics 86(3): 824-832.

[2] Amato, J. and Laubach, T., (1999), 'Monetary policy in an estimated optimization-based model with sticky prices and wages', Federal Reserve Bank of Kansas City Research Working Paper 99-09. 
[3] Arias, A., Hansen, G. and Ohanian, L., (2007), 'Why have Business Cycle Fluctuations Become less Volatile?', Economic Theory 32: 43-58.

[4] Ball, L., and Sheridan, N., (2005), 'Does Inflation Targeting Matter?', in Bernanke, B. and Woodford, M., eds., The Inflation Targeting Debate, University of Chicago Press.

[5] Benati, L. and Mumtaz, H., (2008), 'The Great Stability in the UK: Good Policy or Good Luck?', Journal of Money, Credit and Banking, 40(1): 121-147.

[6] Benati, L., and P. Surico, (2009), 'VAR Analysis and the Great Moderation', American Economic Review 99, pp. 1636-52,

[7] Bergin, P., (2003), 'Putting the new open economy macroeconomics to a test', Journal of International Economics 60: 3-34.

[8] Bernanke, B., Laubach, T., Mishkin, F. and Posen, A., (1999), Inflation Targeting: Lessons from the International Experience, Princeton: Princeton University Press.

[9] Bernanke, B. and Mihov, I., (1998), 'Measuring Monetary Policy', Quarterly Journal of Economics 113:869902.

[10] Boivin, J. and Giannoni, M., (2006), 'Has Monetary Policy Become More Effective?', Review of Economics and Statistics 88(3): 445-462.

[11] Canova, F., and Gambetti, L., (2009), 'Structural Changes in the US Economy: Is There a Role for Monetary Policy?", Journal of Economic Dynamics and Control 33(2):477-490.

[12] Cecchetti, S. and Debelle, G., (2006), 'Has the Inflation Process Changed?', Economic Policy 21: 311-316.

[13] Chari, V., Kehoe, P. and McGrattan, E., (2007), 'Business Cycle Accounting', Econometrica, 75:3.

[14] Christiano, L., Eichenbaum, M. and Evans, C., (2005), 'Nominal Rigidities and the Dynamic Effect of a Shock to Monetary Policy', Journal of Political Economy 113: 1-45.

[15] Clarida, R., Gali, J. and Gertler, Mark, (1998), 'Monetary policy in practice: some international evidence', European Economic Review 42: 1033-1067.

[16] - , (2000), 'Monetary policy rules and macroeconomic stability: evidence and some theory', Quarterly Journal of Economics 115: 147-80. 
[17] Cogley, T. and Sargent, T., (2005), 'Drifts and volatilities: Monetary policies and outcomes in the post WWII US', Review of Economic Dynamics 8: 262-302.

[18] Del Negro, M., Schorfheide, F., Smets, F. and Wouters, R., (2006), 'On the fit of New Keynesian Models', Journal of Business and Economic Statistics 25: 123-162.

[19] Dodge, D., (2002), Remarks prepared for the Central Bank Governor's Panel on Inflation Targeting at a joint session of The American Economic Association, Atlanta, Georgia, 5 January.

[20] Eichenbaum, M., L.P. Hansen, and K. Singleton (1988), 'A Time Series Analysis of Representative Agent Models of Consumption and Leisure Choice under Uncertainty', Quarterly Journal of Economics 103: 51-78.

[21] Erceg, C., Henderson, D. and Levin, A., (1999), 'Optimal monetary policy with staggered wage and price contracts', Journal of Monetary Economics 46: 281-313.

[22] Fortin, P., (1996), 'The Great Canadian Slump', Canadian Journal of Economics 29: 761-787.

[23] Fuhrer, J., (2000), 'Habit Formation in Consumption and Its Implications for Monetary-Policy Models', American Economic Review 90(3): 367-90.

[24] Gali, Jordi and Gertler, M., (1999), 'Inflation dynamics: a structural econometric analysis', Journal of Monetary Economics 44: 195-222.

[25] Gali, Jordi and Monacelli, T., (2005), 'Monetary policy and exchange rate volatility in a small open economy', Review of Economic Studies, 72:3.

[26] Goncalves, C. E. and Carvalho, A., (2009), 'Inflation targeting matters: evidence from OECD sacrifice ratios', Journal of Money, Credit and Banking 41: 233-243.

[27] Hall, R., (1997), 'Macroeconomic Fluctuations and the Allocation of Time', Journal of Labor Economics 15(1): S223-S249.

[28] Justiniano, A. and Primiceri, G., (2006), 'The Time-Varying Volatility of Macroeconomic Fluctuations', American Economic Review, forthcoming.

[29] King, R. and Rebelo, S., (1998) 'Resuscitating real business cycle', in Woodford, M. and Taylor, J., eds., Handbook of Macroeconomics, Amsterdam: North-Holland.

[30] Kollmann, R., (2001), 'The Exchange Rate in a Dynamic-Optimizing Business Cycle Model with Nominal Rigidities: A Quantitative Investigation', Journal of International Economics 55: 243-262. 
[31] Kuttner, K. and Posen, A., (1999), 'Does talk matter after all? Inflation targeting and central bank behaviour', Federal Reserve Bank of New York Staff Reports 88.

[32] Ireland, P., (2004), 'A method for taking models to the data', Journal of Economic Dynamics and Control 28: $1205-1226$.

[33] Levin, A., Natalucci, F., and Piger, J., (2004), 'The Macroeconomic Effect of Inflation Targeting', Federal Reserve Bank of St. Louis Review 86(4): 51-81.

[34] Longworth, D., (2002), 'Inflation and the Macroeconomy: Changes from the 1980s to the 1990s', Bank of Canada Review Spring: 3-20.

[35] Mishkin, F., (1999), 'International Experiences with Different Monetary Policy Regimes', Journal of Monetary Economics 43(3): 579-606.

[36] - and Posen, A., (1997), 'Inflation targeting: lessons from four countries', Federal Reserve Bank of New York Economic Policy Review, August.

[37] Mishkin, F. and Schmidt-Hebbel, Klaus, (2002): 'A Decade of Inflation Targeting in the World: What Do We Know and What Do We Need to Know?', in Norman Loayza and Raimundo Soto, eds.: Inflation Targeting: Design, Performance, Challenges, Central Bank of Chile.

[38] Monacelli, T. , (2005), 'Monetary Policy in a Low Pass-Through Environment', Journal of Money Credit and Banking, 37, 1047-1066.

[39] Murray, J., (2006), "Future Trends in Inflation Targeting: A Canadian Perspective", proceedings from the conference Inflation Targeting: Problems and Opportunities, Bank of Canada.

[40] Neumann, M. and von Hagen, J., (2002), 'Does Inflation Targeting Matter?', Federal Reserve Bank of St. Louis Review 84(4): 91-111.

[41] Primiceri, G., (2005), 'Time Varying Structural Vector Autoregressions and Monetary Policy', The Review of Economic Studies, 72: 821-852.

[42] Rabanal, P., (2001), 'Real Wage Rigidites, Endogenous Persistence and Optimal Monetary Policy', mimeo, La Caixa Research Department.

[43] Rabanal, P. and Rubio-Ramirez, J., (2005), 'Comparing New Keynesian Models of the Business Cycle: a Bayesian Approach', Journal of Monetary Economics 52: 1150-1162. 
[44] Ravenna, F., (2007), 'VAR Representations of DSGE Models', Journal of Monetary Economics, 54: 20482064.

[45] Rotemberg, J. and Woodford, M., (1998), 'An optimization-based econometric framework for the evaluation of monetary policy', in B. Bernanke and J. Rotemberg, eds., NBER Macroeconomics Annual 1997, MIT Press.

[46] Sargent, T., (1989), 'Two models of measurements and the investment accelerator', Journal of Political Economy 21: 3-16.

[47] - , (1999), The Conquest of American Inflation, Princeton University Press: Princeton, N.J.

[48] Sims, C., (1999), 'Matlab Optimization Software', mimeo, Princeton University.

[49] Sims, C., and Zha, T., (2006), 'Were There Regimes Switches in US Monetary Policy?', American Economic Review, 96:1.

[50] Smets, F. and Wouters, R., (2005), 'Comparing shocks and frictions in US and Euro area business cycles: a Bayesian DSGE approach', Journal of Applied Econometrics 20: 161-183.

[51] Stock, J., and Watson, M., (2003), 'Has the Business Cycle Changed and Why?', in Gertler, M. and Rogoff, K., eds., NBER Macroeconomics Annual 2002, MIT Press.

[52] Truman, E., (2003), Inflation Targeting in the World Economy, Institute of International Economics.

\section{Appendix}

\subsection{Data Sources and Definitions}

All data are sampled at quarterly frequency. Growth, inflation and interest rates are not annualized. Unless otherwise specified, data for Canada is obtained from the CANSIM database, and US data is obtained from the Federal Reserve Bank of St. Louis FRED database.

Canada Output: Constant prices chain-weighted GDP, SA. Consumption: Constant prices chainweighted personal consumption expenditure, SA. Exports: constant prices chain-weighted exports of goods and services, SA. Imports: constant prices chain-weighted imports of goods and services, SA. Interest rate: Threemonth Treasury bill tender rate, monthly average. Core inflation (CPIX): all items CPI less the eight most volatile components and the effect of indirect tax. Inflation net of indirect taxes: all items CPI excluding the effect of indirect taxes, SA. Inflation: all items CPI, SA (OECD Economic Outlook). Money supply: Bank of Canada 
M2 definition. Labor productivity: output per man-hour, business sector, SA. Import prices: Laspeyeres fixed weight import unit value index, BOP basis, SA. Export prices: Laspeyeres fixed weight export unit value index, BOP basis, SA. Nominal exchange rate: Canadian Dollar to US Dollar exchange rate (IMF-IFS). Nominal wage inflation: average hourly earnings for hourly-paid employees, business sector (includes government and excludes not-for-profit and defense sectors), SA. Hours: average weekly hours for hourly-paid employees including overtime, business sector, SA. Emplyment: total payroll employment, business sector, SA. Unit labor cost: business sector, SA. Business sector price index: implicit price deflator, SA.

US Interest rate: Three-month treasury bill secondary market rate. Output: Constant prices chainweighted GDP non-farm business sector, SA (Bureau of Economic Analysis).

\subsection{Policy Rule Estimation}

All data are sampled at quarterly frequency. Growth, inflation and interest rates are not annualized. Over both samples, $y_{t}$ is given by HP-filtered constant-prices GDP, which approximates well the Bank of Canada output gap measure published in the Monetary Policy Reports. The policy interest rate during the inflation targeting period is the overnight rate, but since this series is only available since 1975 we measure $i_{t}$ with the 3 -month Canadian T-bill rate. The two rates are very highly correlated. Since inflation targeting was adopted, the Bank of Canada uses a measure of inflation excluding the impact of indirect taxes and the eight most volatile components as an operational target, and this is the inflation rate used for the $\pi_{t}$ series. In the earlier sample the measure of inflation $\pi_{t}$ is built using the seasonally adjusted total CPI measure net of indirect taxes, available starting in January 1984, and the seasonally adjusted total CPI index, which starts as early as 1961. Specifications of the policy rule allowing for the monetary authority to react to the US-Canadian dollar exchange resulted in an estimated feedback coefficient not significantly different from zero.

\subsection{VAR Representation of DSGE models}

The DSGE rational expectations equilibrium for $x_{t}, z_{t}, y_{t}$ can be written as the system (13), (14) by assuming $q_{t}=y_{t}$. To obtain the equilibrium law of motion in eq. (1) write:

$$
\begin{aligned}
Y_{t} & =\Gamma_{1} Y_{t-1}+\Gamma_{2} z_{t} \\
z_{t} & =N z_{t-1}+\varepsilon_{t} \\
Y_{t} & =\left[\begin{array}{l}
x_{t} \\
y_{t}
\end{array}\right] ; \Gamma_{1}=\left[\begin{array}{ll}
F^{11} & 0 \\
H^{\prime 1} & 0
\end{array}\right] ; \Gamma_{2}=\left[\begin{array}{c}
F^{12} \\
H^{\prime 2}
\end{array}\right] ; N=\left[F^{22}\right]
\end{aligned}
$$


where the vector $Y_{t}^{\prime}=\left[x_{t}, y_{t}\right]$ has dimension $1 \times n+r$. Assume the vector $z_{t}$ has dimension $m=n+r$, therefore the number $n+r$ of observable variables is equal to the number of shocks, and the matrix $\Gamma_{2}$ is square (see Ravenna, 2007, for details on the non-square case). Since:

$$
z_{t}=\Gamma_{2}^{-1} Y_{t}-\Gamma_{2}^{-1} \Gamma_{1} Y_{t-1}=N\left[\Gamma_{2}^{-1} Y_{t-1}-\Gamma_{2}^{-1} \Gamma_{1} Y_{t-2}\right]+\varepsilon_{t}
$$

we obtain a $\operatorname{VAR}(2)$ representation for eq. (29):

$$
\begin{aligned}
Y_{t} & =\left(\Gamma_{1}+\Gamma_{2} N \Gamma_{2}^{-1}\right) Y_{t-1}-\left(\Gamma_{2} N \Gamma_{2}^{-1} \Gamma_{1}\right) Y_{t-2}+\Gamma_{2} \varepsilon_{t} \\
& =\bar{\Gamma}_{1} Y_{t-1}+\bar{\Gamma}_{2} Y_{t-2}+\eta_{t}
\end{aligned}
$$

If $N=[0]$ the $\operatorname{VAR}(2)$ in eq. (30) simplifies to the $\operatorname{VAR}(1)$ in eq. (1). Typically DSGE models have a larger number of observable variables than unobservable shocks, that is $m<n+r$. In this case a non-singular VAR representation for the observable variables can still be obtained by including only an $m$-dimensional subset of the vector $Y_{t}$. In general, for the DSGE equilibrium to have a finite-order VAR representation $Y_{t}$ must include all the elements of the vector $x_{t}$ (see Ravenna, 2007).

In the case where part of the variance of $Y_{t}$ is explained by random shocks not included in the DSGE model we have that $Y_{t}=\Gamma_{1} Y_{t-1}+\Gamma_{2} z_{t}+C w_{t}$ where $w_{t}$ is a vector white noise. Then

$$
\begin{aligned}
Y_{t} & =\left(\Gamma_{1}+\Gamma_{2} N \Gamma_{2}^{-1}\right) Y_{t-1}-\left(\Gamma_{2} N \Gamma_{2}^{-1} \Gamma_{1}\right) Y_{t-2}+\Gamma_{2} \varepsilon_{t}-\Gamma_{2} N \Gamma_{2}^{-1} C w_{t-1}+C w_{t} \\
& =\bar{\Gamma}_{1} Y_{t-1}+\bar{\Gamma}_{2} Y_{t-2}+\eta_{t}+\widetilde{w}_{t}
\end{aligned}
$$

where $\widetilde{w}_{t}=\left[C w_{t}-\Gamma_{2} N \Gamma_{2}^{-1} C w_{t-1}\right]$. For $N=[0]$ and $C=I$ eq. (31) simplifies to eq. (2).

\subsection{DSGE Model Solution Method under Private Sector Incorrect Believes}

Assume a DSGE model is described by the system of stochastic difference equations:

$$
\begin{aligned}
0 & =A E_{t}\left(Y_{t+1}\right)+B Y_{t}+C Y_{t-1}+D z_{t} \\
z_{t} & =N z_{t-1}+\varepsilon_{t}
\end{aligned}
$$

Define the rational expectation equilibrium for $Y_{t}$ under the monetary policy rule $L_{a}$ as:

$$
Y_{t}=\Gamma_{a 1} Y_{t-1}+\Gamma_{a 2} z_{t}
$$


where $z_{t}=N z_{t-1}+\varepsilon_{t}$. If the private sector expects the central bank to behave according to the policy rule $L_{b}$, expectations are consistent with the rational expectation equilibrium for $Y_{t}$ defined by:

$$
Y_{t}=\Gamma_{b 1} Y_{t-1}+\Gamma_{b 2} z_{t}
$$

Let $\tilde{E}_{t}^{L}$ indicate the expectation of a variable under the belief that the central bank follows the policy rule $L$. The structural model (32) for $Y_{t}$ can then be written as:

$$
\begin{aligned}
0 & =A \tilde{E}_{t}^{b}\left(Y_{t+1}\right)+B Y_{t}+C Y_{t-1}+D z_{t} \\
& =A\left[\Gamma_{b 1} Y_{t}+\Gamma_{b 2} N z_{t}\right]+B Y_{t}+C Y_{t-1}+D z_{t}
\end{aligned}
$$

The model (35) can be solved for $Y_{t}$. For any policy $L_{a} \neq L_{b}$ the solution for (35) will be different from the reduced-form law of motion (34). If the central bank's policy $L_{a}$ is specified in terms of expected inflation, the DSGE model under incorrect private sector believes is given by:

$$
0=A\left[\Gamma_{b 1} Y_{t}+\Gamma_{b 2} N z_{t}\right]+A^{c b} E_{t}\left(Y_{t+1}\right)+B Y_{t}+C Y_{t-1}+D z_{t}
$$

The expectation term appears because the central bank's instrument reacts to the rational expectation inflation forecast. $A^{c b}$ includes the coefficients on the central bank's expected values of $Y_{t+1}$ in the policy rule. Solving the model (36) for the rational expectations equilibrium yields the law of motion for $Y_{t}$ :

$$
Y_{t}=\Gamma_{c 1} Y_{t-1}+\Gamma_{c 2} z_{t}
$$

which assumes the central bank knows the private sector incorrect believes about the policy regime $L$, and takes them into account when formulating its own inflation forecast.

\subsection{Building Policy Shock Series to Achieve Historical Inflation Path}

Let $q_{t}^{i}$ define the $i^{t h}$ row of the vector $q_{t}$ and $q_{t}^{-i}$ the vector including all the rows of $q_{t}$ except the $i^{t h}$ one, which we assume is the row corresponding to the inflation variable. Eqs. (25), (26) imply that for any counterfactual 
path $\xi_{t}^{1 \prime}$ and Kalman-filtered estimate $\xi_{t \mid T}^{2}$ :

$$
\begin{aligned}
\bar{\xi}_{t}^{1} & =\bar{F}^{11} \bar{\xi}_{t-1}^{1}+\bar{F}^{12} \xi_{t-1 \mid T}^{2} \\
q_{t}^{i} & =\bar{H}^{\prime 1 i} \bar{\xi}_{t}^{1}+\bar{H}^{2 i} \xi_{t \mid T}^{2}=\bar{H}^{\prime 1 i} \bar{F}^{11} \bar{\xi}_{t-1}^{1}+\bar{H}^{\prime 1 i} \bar{F}^{12} \xi_{t-1 \mid T}^{2}+\bar{H}^{\prime 2 i} \xi_{t \mid T}^{2} \\
& =\bar{H}^{\prime 1 i} \bar{F}^{11} \bar{\xi}_{t-1}^{1}+\bar{H}^{\prime 1 i} \bar{F}^{12} \xi_{t-1 \mid T}^{2}+\bar{H}^{\prime 2 i^{-j}} \xi_{t \mid T}^{2^{-j}}+\bar{H}^{\prime 2 i^{j}} \xi_{t \mid T}^{2^{j}}
\end{aligned}
$$

where $\bar{H}^{\prime 1 i}\left(\bar{H}^{\prime 2 i}\right)$ is the $i^{t h}$ row of the matrix $\bar{H}^{\prime 1}\left(\bar{H}^{\prime 2}\right), \bar{H}^{\prime 2 i^{j}}$ is the $j^{\text {th }}$ column of the matrix $\bar{H}^{\prime 2 i}, \bar{H}^{\prime 2 i^{-j}}$ is a matrix including all the columns of $\bar{H}^{\prime 2 i}$ except the $j^{\text {th }}$, which we assume is the column corresponding to the policy shock variable $\xi_{t \mid T}^{2^{j}}$, and $\xi_{t \mid T}^{2^{-j}}$ is the vector composed of all the elements of $\xi_{t \mid T}^{2}$ except the $j^{t h}$ one. By setting the variable $\bar{q}_{t}^{i}$ equal to its historical smoothed estimate $q_{t \mid T}^{i}$ eq. (37) can be solved recursively for the shock $\widehat{\xi}_{t}^{2^{j}}=\widehat{\varepsilon}_{i, t}$ :

$$
\widehat{\xi}_{t}^{2^{j}}=\left(\bar{H}^{\prime 2 i^{j}}\right)^{-1}\left[q_{t \mid T}^{i} \bar{H}^{\prime 1 i}-\bar{F}^{11} \bar{\xi}_{t-1}^{1}-\bar{H}^{\prime 1 i} \bar{F}^{12} \xi_{t-1 \mid T}^{2}-\bar{H}^{\prime 2 i^{-j}} \xi_{t \mid T}^{2^{-j}}\right]
$$

Since it is assumed that for the inflation equation $w_{t}^{i}=0 \forall t$, it follows that $q_{t \mid T}^{i}=q_{t}^{o^{i}}$ and $\widehat{\xi}_{t}^{2^{j}}$ is the value of the policy shock ensuring that inflation equals its historical value in the counterfactual history where the dynamics of the economy is described by the matrices $\bar{F}^{11}, \bar{F}^{12}, \bar{H}^{\prime}$.

\subsection{Market Clearing and Aggregate Equilibrium Conditions for the DSGE model}

The household's intratemporal optimality condition for consumption allocation is $\frac{C_{F, t}}{C_{H, t}}=\frac{\gamma}{1-\gamma}\left(S_{t}\right)^{-\rho}$ where $S_{t}=P_{F, t} / P_{H, t}$. Euler equations for domestic and foreign riskless bonds can be combined to give:

$$
\begin{aligned}
0 & =E_{t}\left\{M U C_{t+1} \frac{P_{t}}{P_{t+1}}\left[\frac{e_{t+1}}{e_{t}}\left(1+i_{t}^{*}\right)-\left(1+i_{t}\right)\right]\right\} \\
M U C_{t} & =E_{t}\left[\frac{D_{t}}{C_{t}-b C_{t-1}}-\beta b \frac{D_{t+1}}{C_{t+1}-b C_{t}}\right]
\end{aligned}
$$

where $M U C_{t}$ is the marginal utility of consumption, $\left(1+i_{t}\right)=v_{t}^{-1}$ is the gross nominal interest rate and $\left(1+i_{t}^{*}\right)=v_{t}^{*^{-1}}$ is the interest rate paid by domestic residents to borrow on the international capital market.

Market clearing in the domestic economy requires

$$
Y_{H, t}=\int_{0}^{1} A_{t} N_{t}(i) d i=A_{t} N_{t}=\int_{0}^{1}\left[\frac{P_{H, t}(i)}{P_{H, t}}\right]^{-\vartheta}\left(C_{H, t}+C_{H, t}^{*}\right) d i
$$

or $Y_{H, t}=\left(C_{H, t}+C_{H, t}^{*}\right) s_{t}$ where $s_{t}=\int_{0}^{1}\left[\frac{P_{H, t}(i)}{P_{H, t}}\right]^{-\vartheta} d i$. Since all firms face identical marginal costs, any firm 
belonging to the fraction $\left(1-\theta_{p}\right)$ resetting the price at $t$ chooses the same new optimal price: $\tilde{P}_{H, t}(i)=\tilde{P}_{H, t}$ and $P_{H, t}^{R T}(i)=P_{H, t}^{R T}$. The solution to the optimal pricing problem is given by:

$$
\tilde{P}_{H, t}(i) E_{t} \sum_{s=0}^{\infty}\left(\theta_{p} \beta\right)^{s} \Lambda_{t, t+s}\left[\frac{\tilde{P}_{H, t}(i)}{P_{H, t+s}}\right]^{1-\vartheta} C_{t+s}^{W}=\frac{\vartheta}{\vartheta-1} E_{t} \sum_{s=0}^{\infty}\left(\theta_{p} \beta\right)^{s} \Lambda_{t, t+s} M C_{t+s}^{N}\left[\frac{\tilde{P}_{H, t}(i)}{P_{H, t+s}}\right]^{1-\vartheta} C_{t+s}^{W}
$$

The CPI index evolves according to:

$$
\begin{aligned}
P_{H, t} & =\left[\theta_{p} P_{H, t-1}^{1-\vartheta}+\left(1-\theta_{p}\right) \bar{P}_{H, t}^{1-\vartheta}\right]^{\frac{1}{1-\vartheta}} \\
\bar{P}_{H, t} & =\left[\omega_{p} P_{H, t}^{R T^{1-\vartheta}}+\left(1-\omega_{p}\right) \widetilde{P}_{H, t}^{1-\vartheta}\right]^{\frac{1}{1-\vartheta}}
\end{aligned}
$$

Each household purchases an equal amount $C_{H, t}^{j}(i)$ so that $C_{H, t}^{j}(i)=C_{H, t}(i)$. Since the marginal rate of substitution between consumption and labor will be equal across all households who can reset the wage at a given time, the wage setting equation (40) implies that all household contracting a new wage at $t$ will choose the same new optimal wage, so that $\tilde{W}_{t}^{j}=\tilde{W}_{t}$. Let $M U N_{t+s}^{j}=\frac{\partial U_{t+s}^{j}}{\partial N_{t+s}^{j}}$. The first order condition for household $j$ is:

$$
E_{t}\left\{\sum_{s=0}^{\infty}\left(\theta_{w}^{s} \beta^{s}\right)\left[\frac{\phi-1}{\phi} M U C_{t+s}^{j} \frac{\tilde{W}_{t}^{j}}{P_{t+s}}\right] N_{t+s}^{j}\right\}=-E_{t}\left\{\sum_{s=0}^{\infty}\left(\theta_{w}^{s} \beta^{s}\right)\left[M U N_{t+s}^{j}\right] N_{t+s}^{j}\right\}
$$

Using the wage index definition and $W_{t}^{R T^{j}}=W_{t}^{R T}$, the aggregate wage index evolves according to:

$$
W_{t}=\left[\theta_{w} W_{t-1}^{1-\phi}+\left(1-\theta_{w}\right)\left(1-\omega_{w}\right) \tilde{W}_{t}^{1-\phi}+\left(1-\theta_{w}\right) \omega_{w} W_{t}^{R T^{1-\phi}}\right]^{\frac{1}{1-\phi}}
$$

Aggregating over firms in the importing sector results in the aggregate foreign-good price index $P_{F, t}$ equal to $\left[\theta_{F} P_{F, t-1}^{1-\vartheta}+\left(1-\theta_{p}\right) \widetilde{P}_{F, t}^{1-\vartheta}\right]^{\frac{1}{1-\vartheta}}$ where $\widetilde{P}_{F, t}$ is the price chosen by re-optimizing firms. The law of motion for the net foreign asset stock $B_{t}^{*}$ can be derived using the households' budget constraints and the market clearing conditions. To ensure stationarity we assume that $i^{*}$ is given by the exogenous world interest rate $\widetilde{i}^{*}$ plus a premium increasing in the real value of the country's stock of foreign debt: $\left(1+i_{t}^{*}\right)=\left(1+\tilde{\imath}_{t}^{*}\right) g\left(-\widetilde{B}_{t}\right)$, where $\widetilde{B}_{t}=\frac{e_{t} B_{t}^{*}}{P_{H, t}}$ and $g(\cdot)$ is a positive, increasing function. 
Table 1: Estimates of the Monetary Policy Rule

\begin{tabular}{l|cccc}
\hline \hline \multicolumn{1}{c}{$\omega_{\pi}$} & $\omega_{y}$ & $\chi$ & $\alpha$ \\
\hline $1971: 1-1990: 4$ & & & & \\
& & & & \\
& 1.09 & 1.21 & 0.91 & -0.08 \\
& $(0.51)$ & $(0.30)$ & $(0.02)$ & $(0.90)$ \\
& & & & \\
& & & & \\
& 2.16 & 0.27 & 0.84 & -0.02 \\
& $(0.72)$ & $(0.09)$ & $(0.03)$ & $(0.34)$ \\
& & & & \\
& & & &
\end{tabular}

Note: Estimate of policy rule $i_{t}=(1-\chi)\left[\omega_{\pi} E_{t} \pi_{t+1}+\omega_{y} y_{t}\right]+\chi i_{t-1}+\varepsilon_{i, t}$ on Canadian quarterly data using GMM estimator with heteroschedasticity and autocorrelation consistent covariance matrix. $\alpha$ is a constant. Standard errors reported in brackets. The instrument set includes four lags of the interest rate, inflation rate, money supply growth rate and three lags of the HP-filtered output. See the Appendix for data sources. 
Table 2: Maxim um Likelihood Estimates

\begin{tabular}{|c|c|c|c|}
\hline Parameter & & Estim ate & Standard Deviation \\
\hline Inverse labor supply elasticity & $\eta$ & 2.65 & 1.82 \\
\hline Price elasticity of demand - foreign basket & $\rho$ & 2.23 & 0.87 \\
\hline Share of rule-of-thumb domestic firms & $\omega_{p}$ & 0.89 & 0.06 \\
\hline Share of rule-of-thumb households & $\omega_{\mathrm{w}}$ & 0.32 & 0.12 \\
\hline Probability of not resetting price - domestic firms & $\theta_{\mathrm{p}}$ & 0.94 & 0.04 \\
\hline Probability of not resetting wage & $\theta_{\mathrm{w}}$ & 0.79 & 0.09 \\
\hline Probability of not resetting price - import sector & $\theta_{\mathrm{F}}$ & 0.73 & 0.07 \\
\hline Habit persistence coefficient & $\mathrm{b}$ & 0.94 & 0.03 \\
\hline AR (1) parameter - technology shock & $\rho_{\mathrm{a}}$ & 0.93 & 0.07 \\
\hline A R (1) parameter - preference shock & $\rho_{d}$ & 0.82 & 0.11 \\
\hline A R (1) parameter - foreign demand shock & $\rho_{\mathrm{c}^{*}}$ & 0.73 & 0.06 \\
\hline A R (1) parameter - foreign good inflation shock & $\rho_{\pi *}$ & 0.96 & 0.02 \\
\hline AR (1) parameter - foreign interest rate shock & $\rho_{\mathrm{i}^{*}}$ & 0.97 & 0.01 \\
\hline \multicolumn{4}{|l|}{ Covariance Matrix $Q$} \\
\hline Technology shock innovation & $\sigma_{\mathrm{a}}$ & 0.47 & 0.09 \\
\hline Preference shock innovation & $\sigma_{d}$ & 5.68 & 3.27 \\
\hline Monetary policy shock innovation & $\sigma_{\mathrm{i}}$ & 0.15 & 0.01 \\
\hline Foreign demand shock innovation & $\sigma_{c^{*}}$ & 1.47 & 0.24 \\
\hline Foreign good inflation shock innovation & $\sigma_{\pi *}$ & 0.14 & 0.04 \\
\hline Foreign interest rate shock innovation & $\sigma i^{*}$ & 0.11 & 0.01 \\
\hline \multirow[t]{3}{*}{ Correlation - foreign shocks innovations } & $\operatorname{corr}\left(c^{*}, \mathrm{i}^{*}\right)$ & 0.56 & 0.11 \\
\hline & $\operatorname{corr}\left(\mathrm{C}^{*}, \pi^{*}\right)$ & -0.31 & 0.21 \\
\hline & $\operatorname{corr}\left(\pi^{*}, \mathrm{i}^{*}\right)$ & 0.46 & 0.19 \\
\hline \multicolumn{4}{|l|}{ Covariance $M$ atrix $R$} \\
\hline Output & $\sigma_{Y h}$ & 1.14 & 0.16 \\
\hline CPI inflation & $\sigma_{\pi}$ & 0.38 & 0.03 \\
\hline Terms of trade & $\sigma_{\mathrm{s}}$ & 2.73 & 0.31 \\
\hline Exchange rate depreciation & $\sigma_{\Delta \mathrm{e}}$ & 2.32 & 0.26 \\
\hline Foreign consumption of domestic good & $\sigma_{c h^{*}}$ & 0.89 & 0.28 \\
\hline W age inflation & $\sigma_{\xi}$ & 0.45 & 0.04 \\
\hline Labor hours & $\sigma_{\mathrm{n}}$ & 0.81 & 0.22 \\
\hline $\mathrm{R}$ eal $\mathrm{m}$ arg in al cost & $\sigma_{m c}$ & 1.02 & 0.16 \\
\hline
\end{tabular}

Note: Maximum likelihood estimates for DSGE model in eqs. (13), (14) and (23). The vector $\left[\sigma_{a_{t}}, \sigma_{d_{t}}, \sigma_{\varepsilon_{i, t}}, \sigma_{C_{t}^{*}}, \sigma_{\pi_{F, t}^{*}}, \sigma_{\tilde{i}_{t}^{*}}\right]$ contains the square root of the main diagonal entries of covariance matrix $Q$ for structural shocks innovations. The vector $\left[\sigma_{Y_{H, t}}, \sigma_{\pi_{t}}, \sigma_{S_{t}}, \sigma_{\Delta e_{t}}, \sigma_{C_{H, t}^{*}}, \sigma_{\xi_{t}}, \sigma_{N_{t}}\right.$, $\sigma_{M C_{t}}$ ] contains the square root of the non-zero main diagonal entries of covariance matrix $R$ for $w_{t}=\left[w_{Y_{H, t}}, w_{\pi_{t}}, w_{i_{t}}, w_{S_{t}}, w_{e_{t} / e_{t-1}}, w_{C_{H, t}^{*}}, w_{\tilde{i}_{t}^{*}}, w_{\xi_{t}}, w_{N_{t}}, w_{M C_{t}}\right]$. Data set includes the variables $\left[Y_{H, t}, \quad \pi_{t}, \quad i_{t}, \quad S_{t}, e_{t} / e_{t-1}, C_{H, t}^{*}, \quad \tilde{i}_{t}^{*}, \quad \xi_{t}, N_{t}, M C_{t}\right]$. Sample: 1991:1 - 2007:2 


\begin{tabular}{|c|c|c|c|}
\hline Model & $\begin{array}{c}\text { Log } \\
\text { likelihood } \\
\text { value }\end{array}$ & $\begin{array}{l}\text { Likelihood } \\
\quad \text { ratio }\end{array}$ & $\mathrm{P}$ value \\
\hline Benchmark model & 757 & - & - \\
\hline Unrestricted model & 649 & $216(202)$ & 0.23 \\
\hline $\begin{array}{l}\text { Restricted covariance matrix R: } \\
{\left[\sigma_{\mathrm{Yh}}=0, \sigma_{\mathrm{p}}=0, \sigma_{\mathrm{ch}^{*}}=0, \sigma_{\mathrm{mc}}=0\right]}\end{array}$ & 797 & $80(4)$ & 0.00 \\
\hline $\begin{array}{l}\text { Flexible domestic producer prices and wages } \\
{\left[\theta_{p}=0, \theta_{w}=0, \omega_{p}=0, \omega_{w}=0\right]}\end{array}$ & 771 & $28(4)$ & 0.00 \\
\hline $\begin{array}{l}\text { Flexible import prices } \\
{\left[\theta_{F}=0\right]}\end{array}$ & 777 & $40(1)$ & 0.00 \\
\hline
\end{tabular}

Note: Likelihood ratio tests with respect to benchmark model. Negative of log-likelihood value reported. Unrestricted model is the model in eqs. (13), (14) and (23) estimated without any restriction on the matrices $F, H, Q, R$. Restricted covariance matrix model assumes the only nonzero variance components of $w_{t}$ are $\left[w_{S_{t}}, w_{e_{t} / e_{t-1}}, w_{\xi_{t}}, w_{N_{t}}\right]$. Degrees of freedom for likelihood ratio statistic reported in brackets. 
Table 4: Inflation statistics

\begin{tabular}{|c|c|c|c|c|}
\hline & $\begin{array}{c}\text { Historical } \\
\text { policy }\end{array}$ & $\begin{array}{c}\text { Counterfactual } \\
\text { policy }\end{array}$ & $\begin{array}{c}\text { Ratio } \\
\text { counterfactual } \\
\text { historical } \\
\end{array}$ & $\begin{array}{c}\text { Difference } \\
\left(\pi_{\text {count }}-\pi_{\text {hist }}\right) \\
\end{array}$ \\
\hline Standard deviation & & & & \\
\hline given ML estimate of covariance matrix $Q$ & 0.98 & 1.59 & 1.62 & \\
\hline Conditional on sample shocks & 0.72 & 0.73 & 1.01 & \\
\hline \multicolumn{5}{|l|}{ No rule-of-thumb firms $\left[\omega_{p}=0\right]$} \\
\hline Conditional standard deviation & 0.75 & 0.80 & 1.08 & \\
\hline \multicolumn{5}{|l|}{ Higher labor supply elasticity $[\eta=1]$} \\
\hline Conditional standard deviation & 0.66 & 1.77 & 2.69 & \\
\hline \multicolumn{5}{|l|}{ Inflation realizations } \\
\hline $1991: 1-2007: 2$ & & & 1.40 & 0.43 \\
\hline $2003: 2-2007: 2$ & & & 2.01 & 0.82 \\
\hline
\end{tabular}

Note: Statistics for smoothed estimate of annual CPI inflation under historical and counterfactual policy rule. Counterfactual policy rule is estimated over the 1971:1 - 1990:4 sample (Table 1). Standard deviation conditional on sample shocks is computed from the realized inflation path given the sample estimate of the Kalman-smoothed shocks vector $\xi_{t \mid T}^{2}$ and the theoretical expectation of inflation. Benchmark model estimates: $\omega_{p}=0.89, \eta=2.66$. Inflation realization statistics report sample average ratio and difference between counterfactual and historical smoothed inflation estimate. Standard deviations reported in percentage points. 
Table 5: Probability of inflation realizations conditional on inflation targeting policy in the period 1991-2007

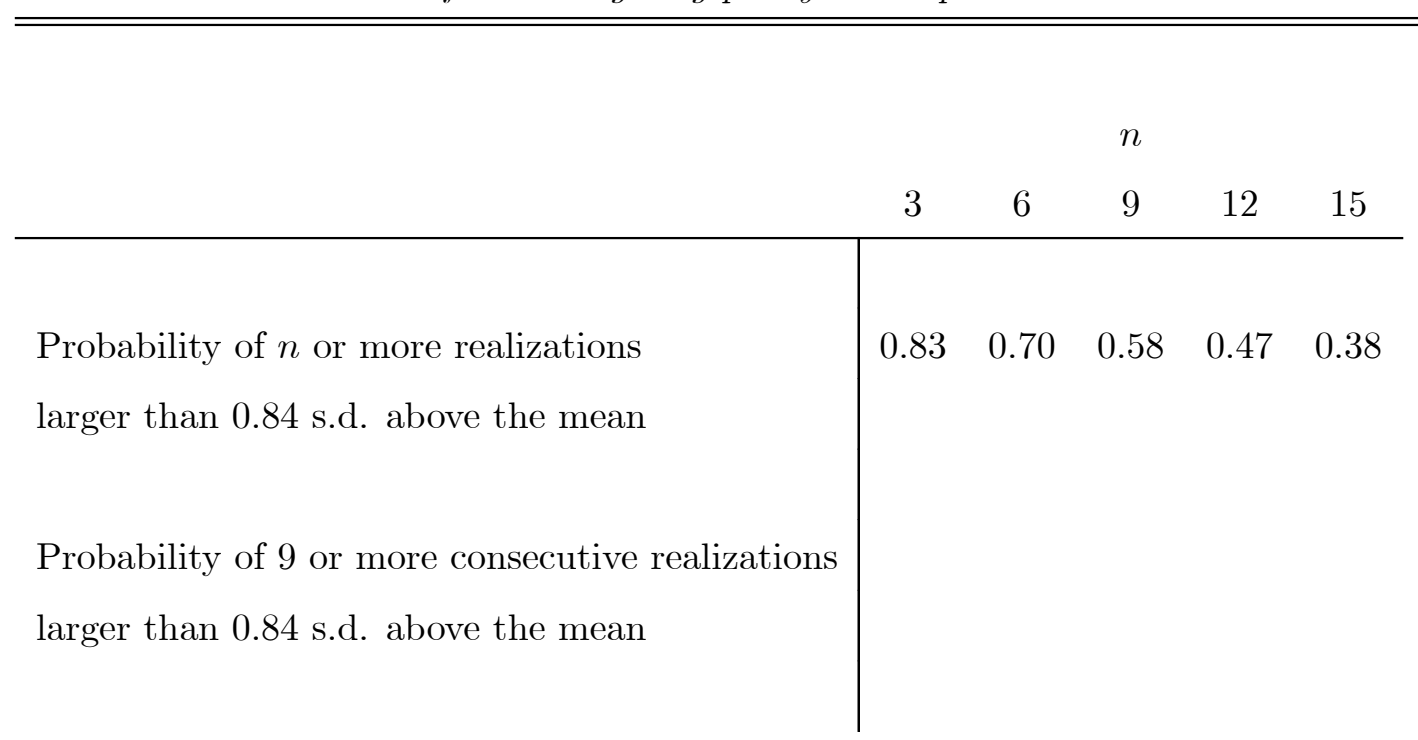

Note: Probability calculated over 25,000 simulations of 66 quarters sample with the model ergodic distribution conditional on the policy rule coefficients estimated over the inflation targeting sample (Table 1). 
Table 6: Inflation forecast error variance decomposition

\begin{tabular}{|c|c|c|c|}
\hline & \multirow[t]{2}{*}{$\operatorname{Corr}(\pi, y)$} & \multicolumn{2}{|c|}{$\begin{array}{l}\text { Inflation forecast error variance } \\
\qquad \text { due to } \tilde{\imath}_{t}^{*}, P_{F, t}^{*} / P_{F, t-1}^{*}, \varepsilon_{i_{t}}\end{array}$} \\
\hline & & estimated & small sample \\
\hline \multicolumn{4}{|l|}{ Shock } \\
\hline Technology & -0.99 & & \\
\hline Preference & -0.55 & & \\
\hline Foreign demand & -0.96 & & \\
\hline Foreign good inflation & 0.04 & & \\
\hline Foreign interest rate & -0.07 & & \\
\hline Monetary policy & 0.14 & & \\
\hline \multicolumn{4}{|l|}{$\begin{array}{l}\text { Variance decomposition } \\
\text { shocks ordering }\end{array}$} \\
\hline$\tilde{\imath}_{t}^{*}, P_{F, t}^{*} / P_{F, t-1}^{*}, C_{t}^{*}, \quad A_{t}, D_{t}, \varepsilon_{i_{t}}$ & & $78 \%$ & $99 \%$ \\
\hline$\tilde{\imath}_{t}^{*}, C_{t}^{*}, P_{F, t}^{*} / P_{F, t-1}^{*}, \quad A_{t}, D_{t}, \varepsilon_{i_{t}}$ & & $79 \%$ & $91 \%$ \\
\hline$P_{F, t}^{*} / P_{F, t-1}^{*}, \tilde{\imath}_{t}^{*}, C_{t}^{*}, \quad A_{t}, D_{t}, \varepsilon_{i_{t}}$ & & $77 \%$ & $98 \%$ \\
\hline$C_{t}^{*}, \tilde{\imath}_{t}^{*}, P_{F, t}^{*} / P_{F, t-1}^{*}, \quad A_{t}, D_{t}, \varepsilon_{i_{t}}$ & & $79 \%$ & $60 \%$ \\
\hline$P_{F, t}^{*} / P_{F, t-1}^{*}, C_{t}^{*}, \tilde{\imath}_{t}^{*}, \quad A_{t}, D_{t}, \varepsilon_{i_{t}}$ & & $78 \%$ & $98 \%$ \\
\hline$C_{t}^{*}, P_{F, t}^{*} / P_{F, t-1}^{*}, \tilde{\imath}_{t}^{*}, \quad A_{t}, D_{t}, \varepsilon_{i_{t}}$ & & $78 \%$ & $61 \%$ \\
\hline
\end{tabular}

Note: First column shows correlation between output and CPI inflation for the estimated model in the case all business cycle volatility were generated by a single shock. Inflation asymptotic forecast error variance decomposition is computed from the exogenous shocks innovations' covariance matrix maximum likelihood estimate (estimated column) and conditional on the smoothed shocks' innovations covariance matrix $\widehat{\widehat{Q}}=\frac{1}{T} \Sigma_{t=1}^{T} \widehat{v}_{t} \widehat{v}_{t}^{\prime}$ over 1991:1 - 2007:2 (small sample column). All results assume the monetary authority enforces the historical policy rule. 

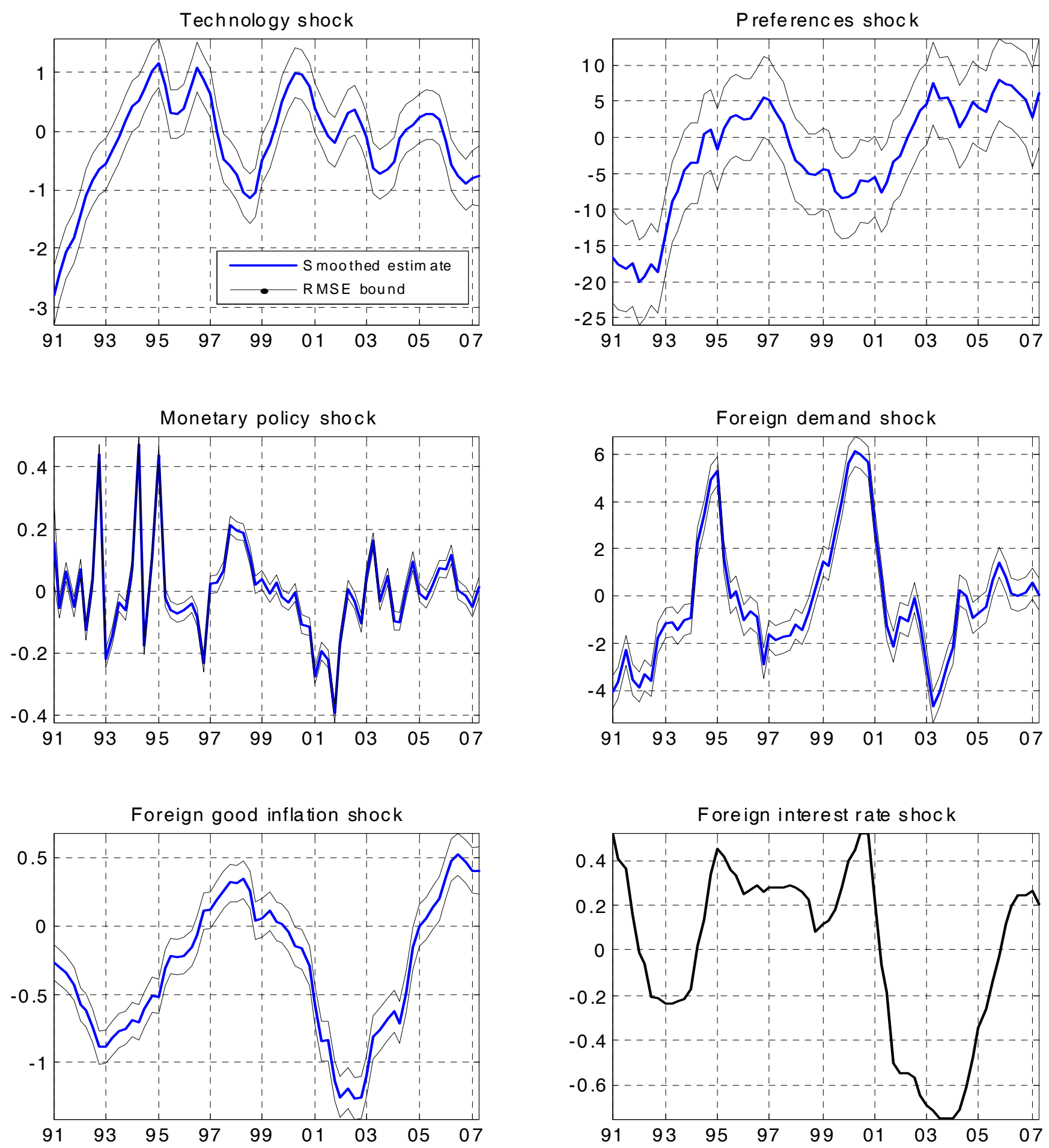

Figure 1: Kalman-smoothed structural shocks vector $\xi_{t}^{2}$, 1991:1 - 2007:2 sample. Law of motion obtained from DSGE model conditional on policy rule coefficients estimated over the inflation targeting sample (Table 1). Light lines plot Root Mean Square Error bands. Scaling in percent. 

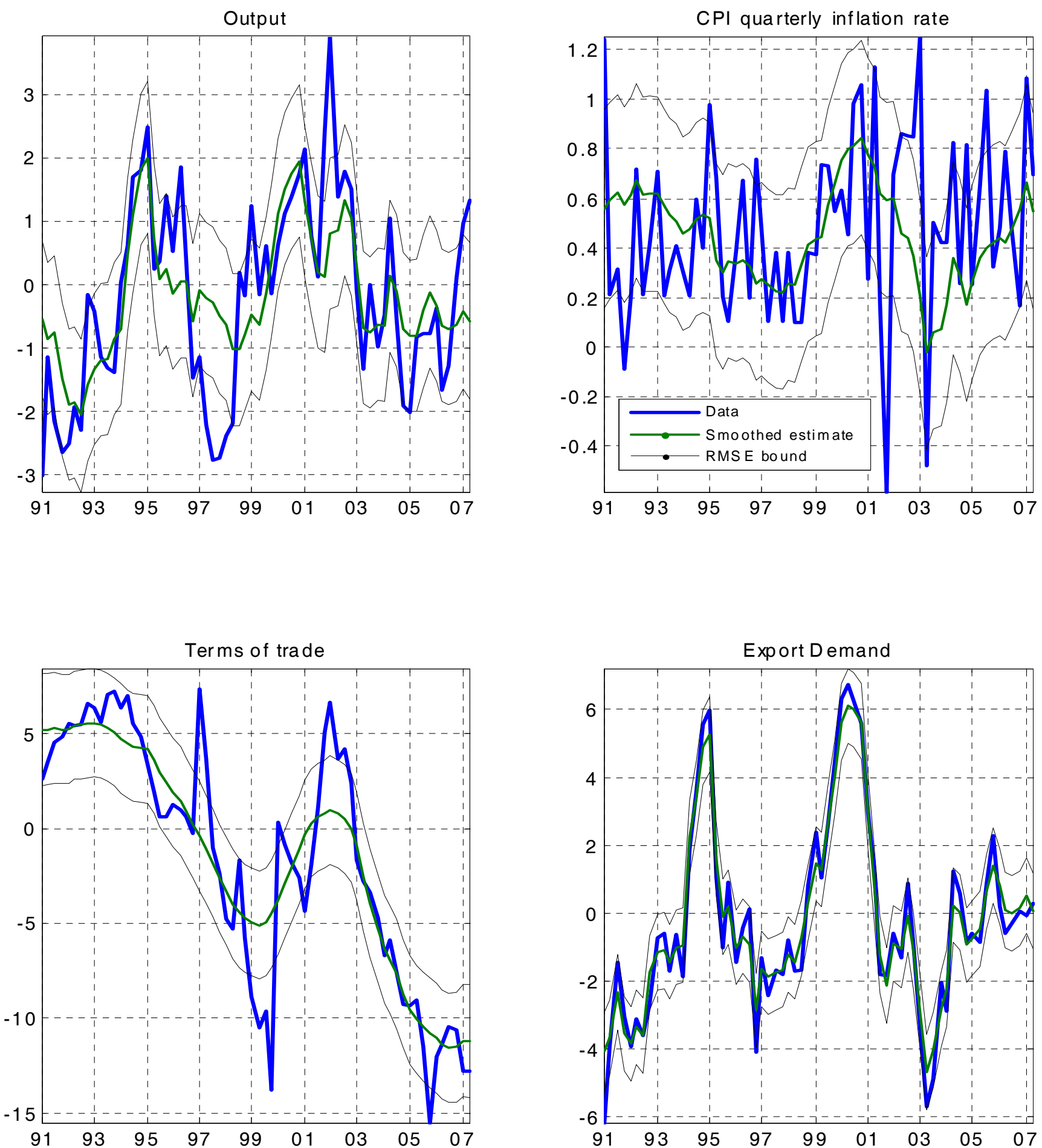

Figure 2: Historical data and Kalman-smoothed estimate. Law of motion obtained from DSGE model conditional on policy rule coefficients estimated over the inflation targeting sample (Table 1). Output is defined as $Y_{H, t}=C_{H, t}+C_{H, t}^{*}$. Light lines plot Root Mean Square Error bands. Scaling in percent. 

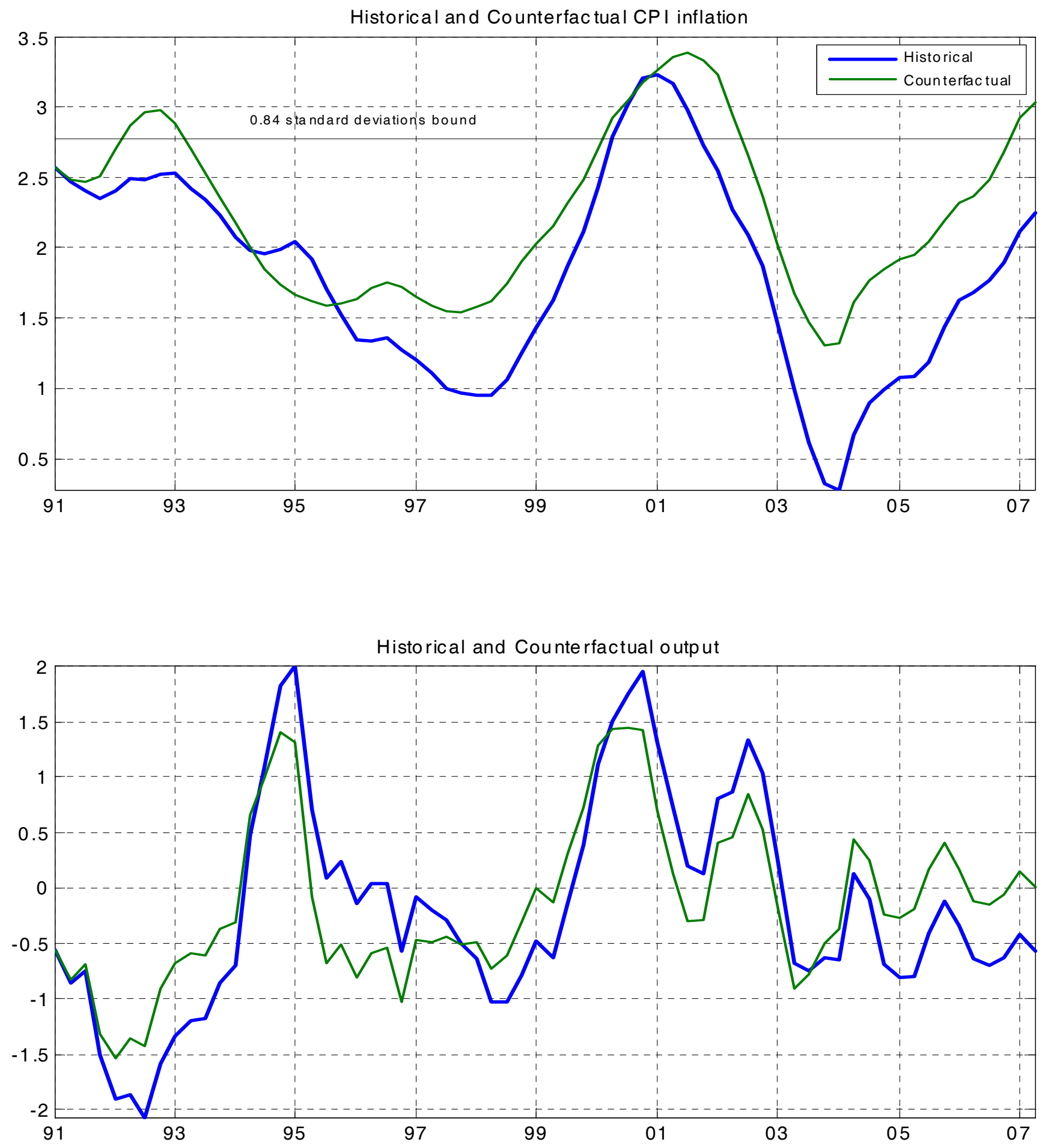

Figure 3: The impact of inflation targeting. Historical series vs. counterfactual under pre-inflation targeting policy. Law of motion for counterfactual path obtained from DSGE model conditional on policy rule coefficients estimated over the sample 1971:1 - 1990:4 (Table 1). The historical inflation measure is the Consumer Price Index net of indirect taxes. Inflation and output historical series are the Kalman-smoothed estimate of the data. Conditional on the inflation targeting policy, realizations of inflation larger than 0.84 standard deviations above the mean are observed with probability $<20 \%$. 
Historical and Counterfactual nominal interest rate - zero policy shocks

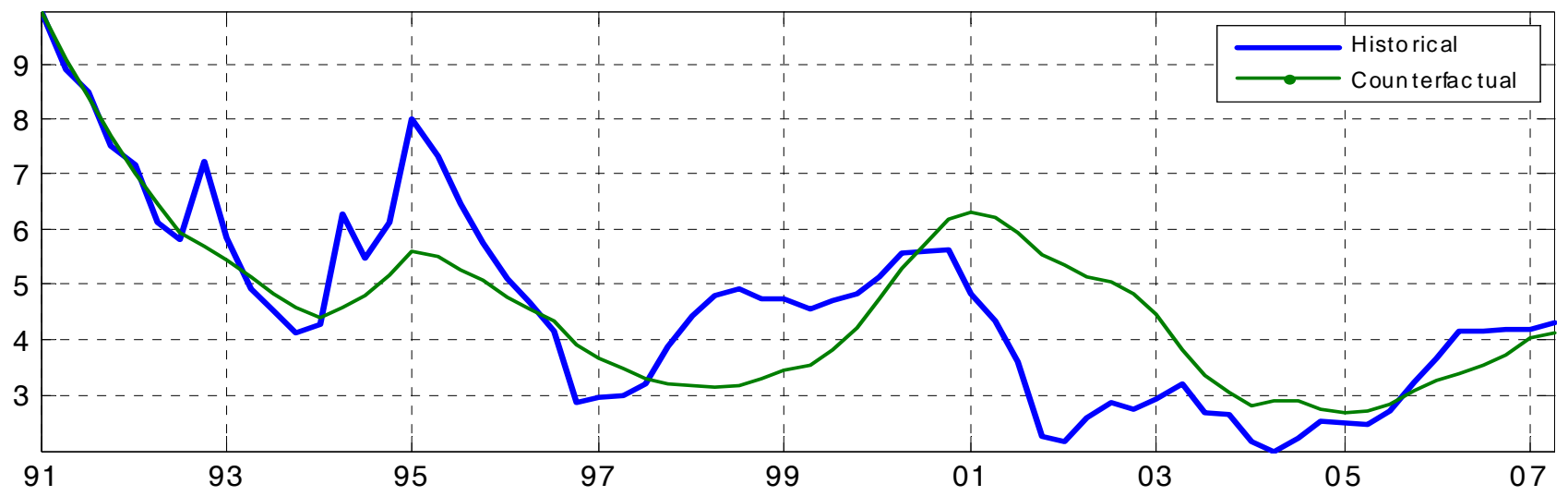

Historical and Counterfactual CPI inflation - zero policy shocks

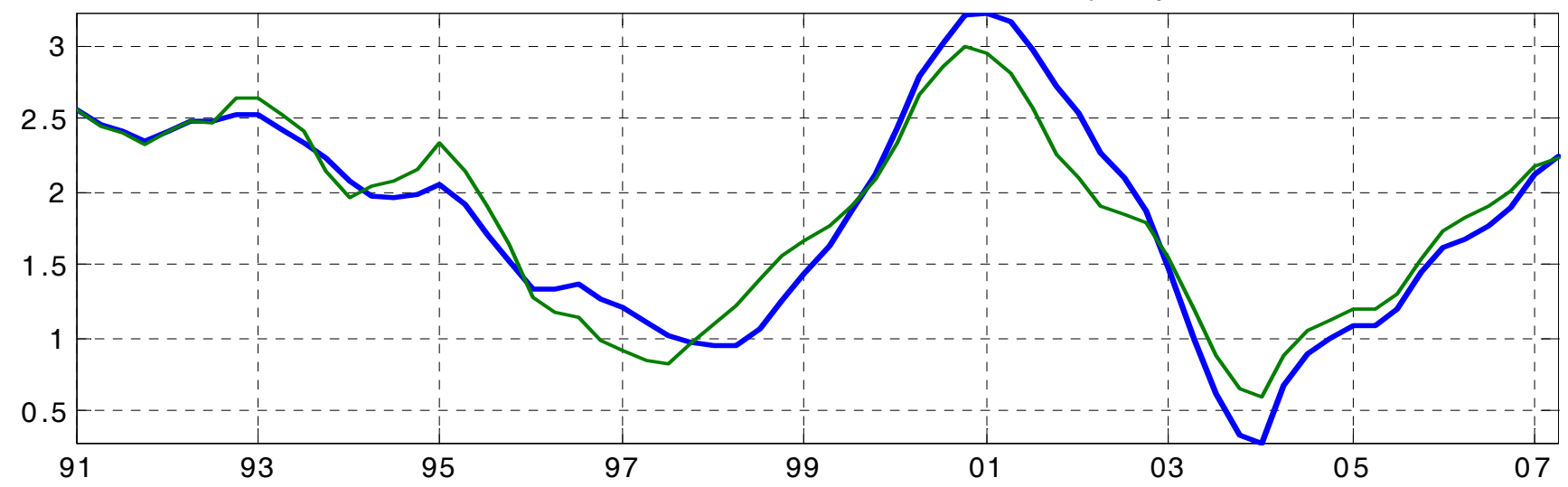

Historic al and Counterfactual output - zero policy shocks

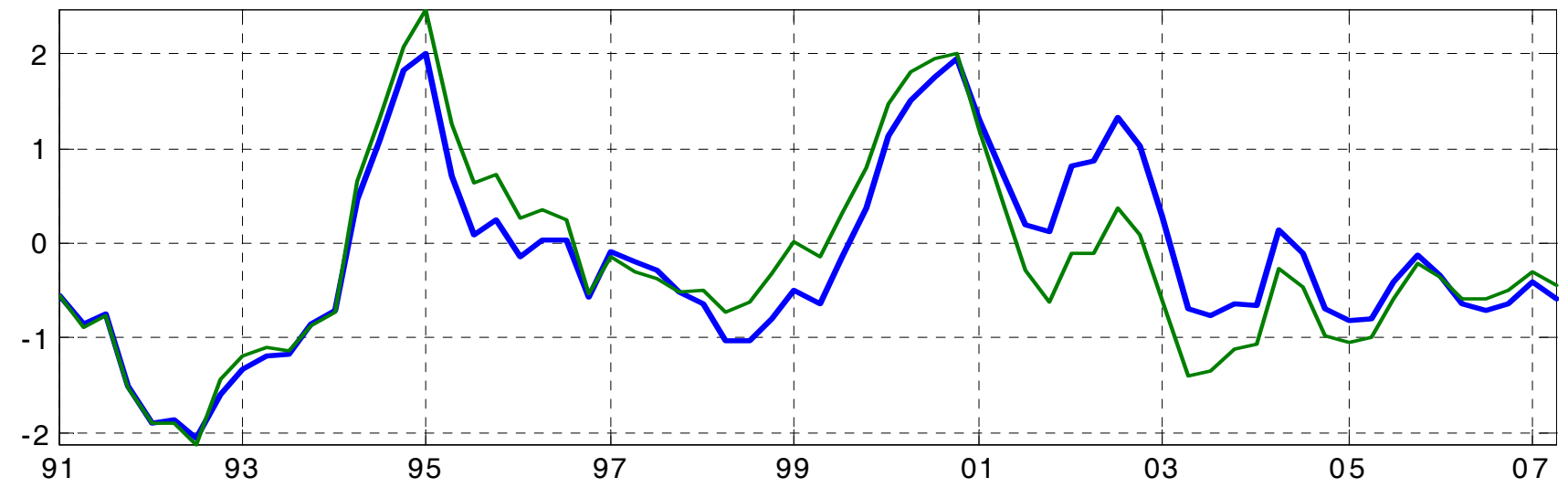

Figure 4: The impact of policy shocks. Historical series vs. counterfactual under inflation targeting policy conditional on policy shock $\varepsilon_{i, t}=0$ in every period. All other components of the shocks vector are set equal to the Kalman-smoothed estimate. Law of motion for counterfactual path obtained from DSGE model conditional on policy rule coefficients estimated over the inflation targeting sample (Table 1). Historical inflation measure is the Consumer Price Index net of indirect taxes. Inflation, output, and interest rate historical series are the Kalman-smoothed estimates of the data. 

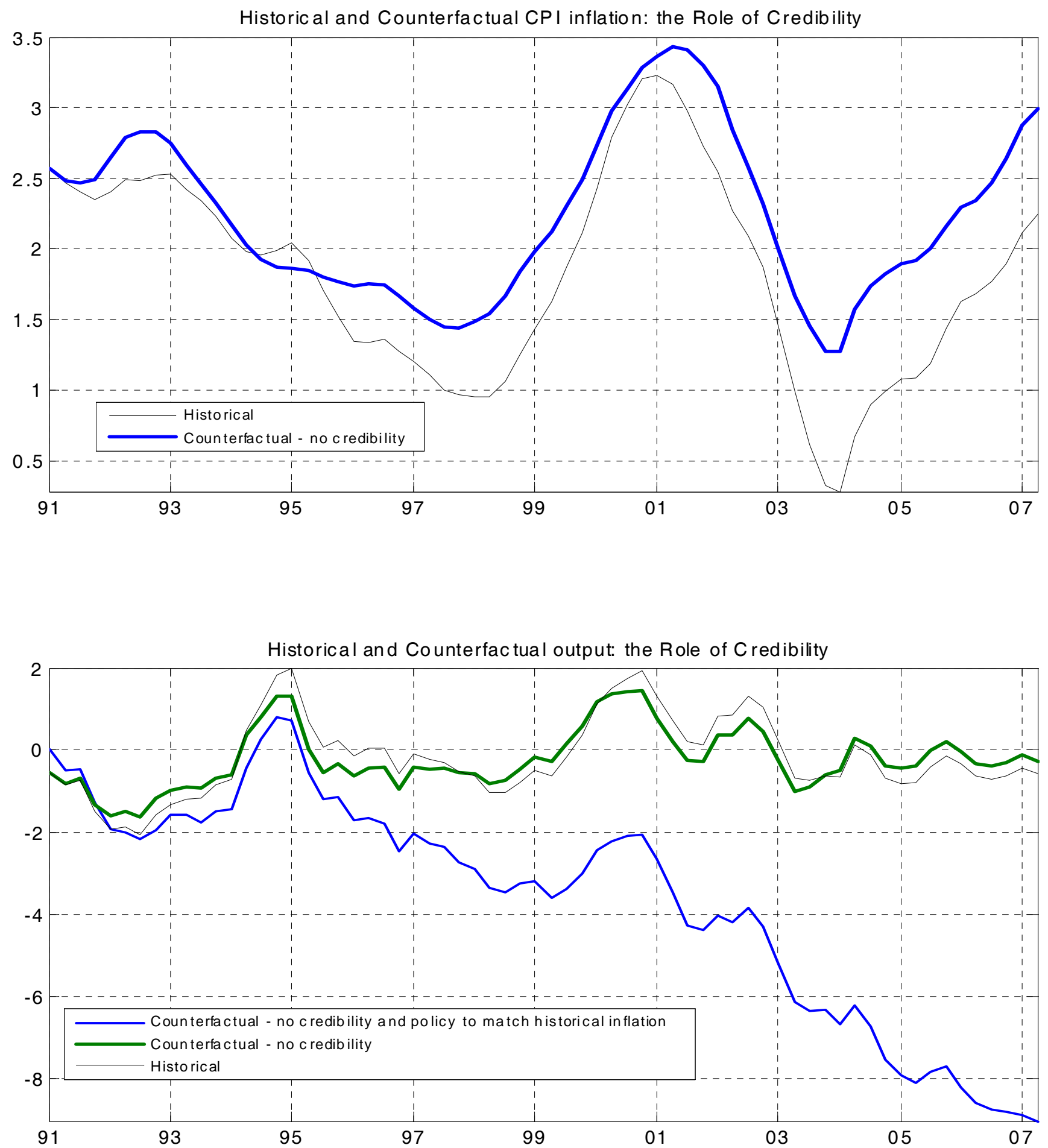

Figure 5: The impact of credibility. Historical series vs. counterfactual under inflation targeting policy when policy change to inflation targeting is not believed by the private sector. Law of motion for counterfactual path obtained from DSGE model conditional on policy rule coefficients estimated over the inflation targeting sample. Private sector expectations are consistent with policy rule coefficients estimated over the sample 1971:1 - 1990:4. Bottom panel plots additional counterfactual output when policy shock $\varepsilon_{i, t}$ is set so that counterfactual inflation follows historical path. 

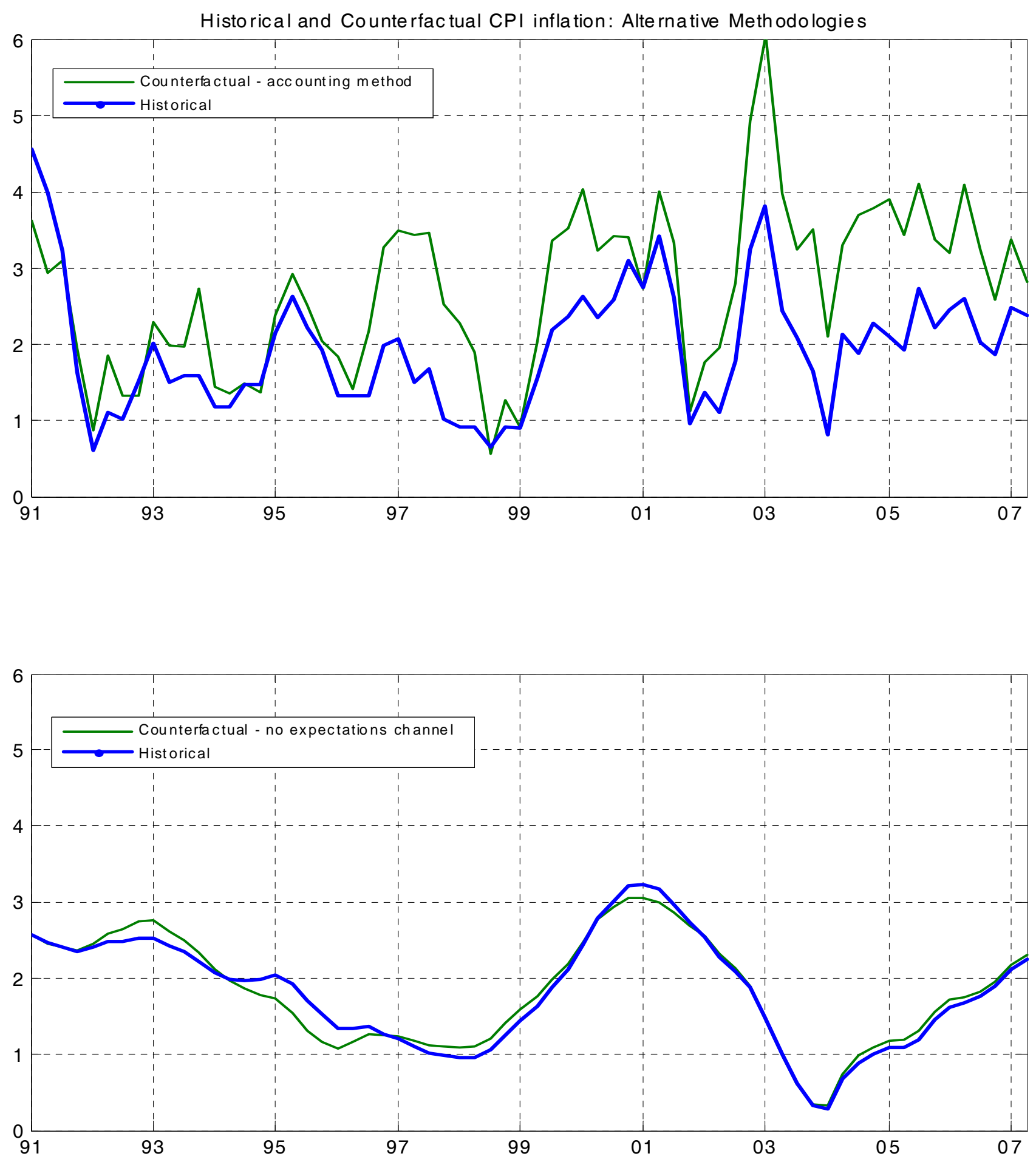

Figure 6: Comparing methodologies to build counterfactuals. Historical series vs. counterfactual under pre-inflation targeting policy. Accounting method series is the counterfactual obtained assuming the only non-zero variance components of $w_{t}$ are $\left[w_{S_{t}}, w_{e_{t} / e_{t-1}}, w_{\xi_{t}}, w_{N_{t}}\right]$. No expectation channel series assumes law of motion is obtained from DSGE model conditional on policy rule coefficients estimated over the sample 1971:1 - 1990:4, while private sector expectations are consistent with policy rule coefficients estimated over the inflation targeting sample. 